NASA Technical Memorandum 102317

AIAA-89-2355

\title{
Mach 5 Inlet CFD and Experimental Results
}

Lois $\mathbf{J}$. Weir

National Aeronautics and Space Administration

Lewis Research Center

Cleveland, Ohio

and

D.R. Reddy and George D. Rupp

Sverdrup Technology, Inc.

NASA Lewis Research Center Group

Cleveland, Ohio

Prepared for the

25th Joint Propulsion Conference

cosponsored by the AIAA, ASME, SAE, and ASEE

Monterey, California, July 10-12, 1989 
MACH 5 INLET CFD AND EXPERIMENTAL RESULTS

\author{
Lois J. Weir* \\ National Aeronautics and Space Administration \\ Lewis Research Center \\ Cleveland, Ohio 44135 \\ and \\ D.R. Reddy ${ }^{\dagger}$ and George D. Rupp ${ }^{\ddagger}$ \\ Sverdrup Technology, Inc. \\ NASA Lewis Research Center Group \\ Cleveland, Ohio 44135
}

\section{ABSTRACT}

An experimental research program was conducted in the NASA Lewis Research Center $10 \mathrm{ft}$. by $10 \mathrm{ft}$. supersonic wind tunnel. The two-dimensional inlet model was designed to study the Mach 3.0 to 5.0 speed range for an "over-under" turbojet plus ramjet propulsion system. The model was extensively instrumented to provide both analytical code validation data as well as inlet performance information. Support studies for the program include flow field predictions with both 3 -dimensional parabolized Navier-Stokes (PNS) and 3D full NavierStokes (FNS) analytical codes. Analytical predictions and experimental results are compared.

\section{NOMENCLATURE}

angle of attack$$
\text { M }
$$

M

p

$\mathbf{P}$

STA

$\mathbf{x}$

y

height

Mach number

static pressure

total pressure

station

axial dimension

vertical dimension

\section{Subscripts}

$\begin{array}{ll}\text { cl } & \text { cowl lip } \\ \text { p } & \text { pitot } \\ 1 & \text { first ramp } \\ \infty & \text { freestream }\end{array}$

*Aerospace Engineer; Member AIAA.

†Supervisor, Turbomachinery Analys is Section; Member AIAA.

\$Wind Tunnel Test Engineer.

\section{BACKGROUND}

In 1980, A joint research program led by NASA Langley with NASA Lewis as a partner, Lockheed California as the prime contractor, and Pratt \& Whitney as subcontractor was initiated which would address critical technology issues in the Mach 3 to 6 speed range. Prior to this time, little focussed research had been done in this flight arena. The specific purpose of the program was to develop a concept for a Mach 5 cruise aircraft, identify the propulsion system required to power it, and define its integration with the aircraft. The aircraft configuration chosen as a result of the study, discussed in Reference 1 and shown in Figure 1 , would employ 4 propulsion modules (two under each wing). The propulsion system chosen for the aircraft is an over/under turbojet plus ramjet system with dualflow, two-dimensional inlet and nozzle.

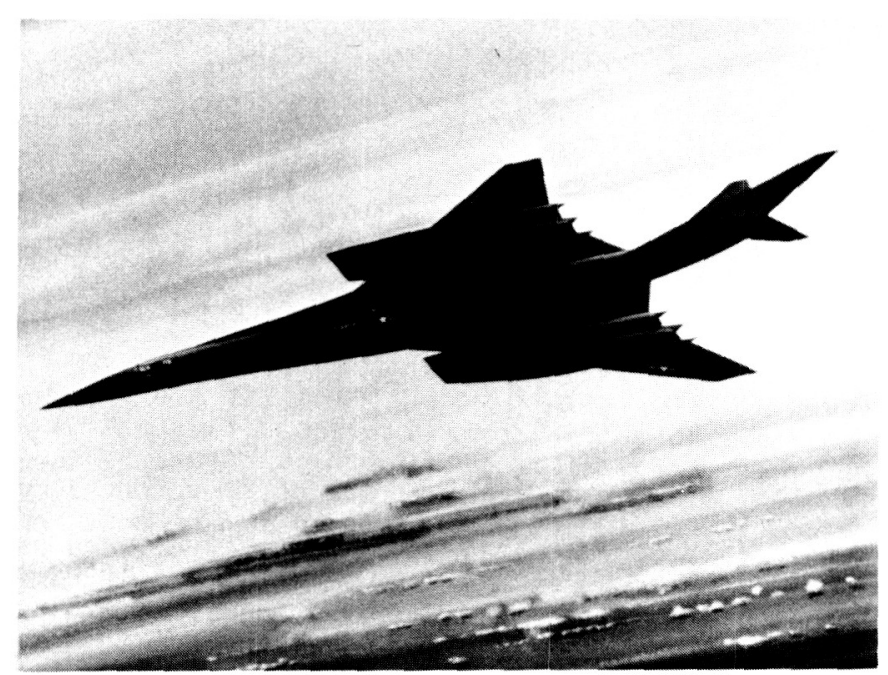

Figure 1: Artist's conception of Mach 5 cruise aircraft

The modes of operation for the over-under turbojet-ramjet system are shown for various flight speeds in Figure 2. The upper flow path of this 


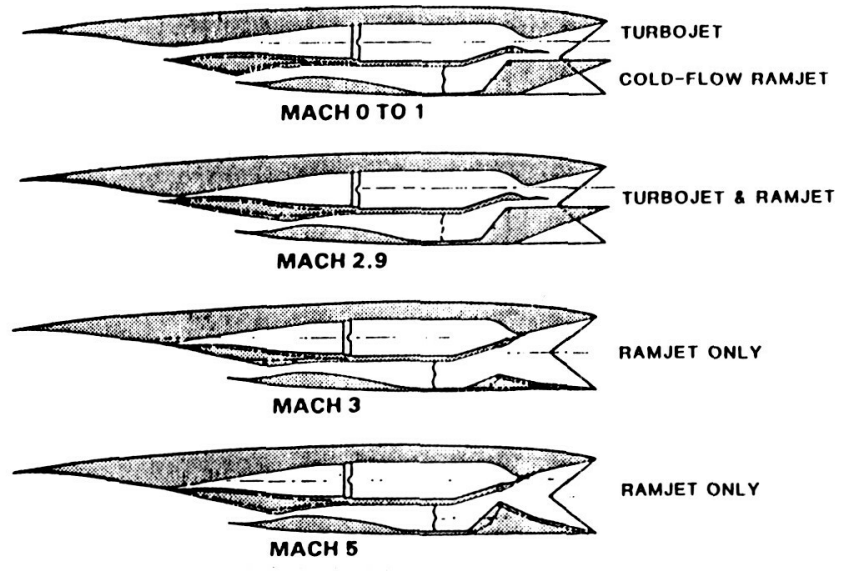

Figure 2: Propulsion system operation

dual-flow system provides airflow to the turbojet engine, which alone powers the aircraft at takeoff, with cold flow through the ramjet in the lower flow path. Near Mach 1, the ramjet is ignited, and both systems operate simultaneously. At Mach 2.5 the turbojet begins to spool down, and near Mach 3, the upper duct closes off completely. Prom Mach 3 to Mach 5 (cruise speed), the ramfet alone powers the vehicle. This propulsion system is designed to take maximum advantage of the turbojet engine in the lower speed range where it is most effective, and the ramjet in the high speed range, where it is most efficient. A discussion of the issues associated with the design of inlets for aircraft in the high supersonic speed range may be found in Reference 2 .

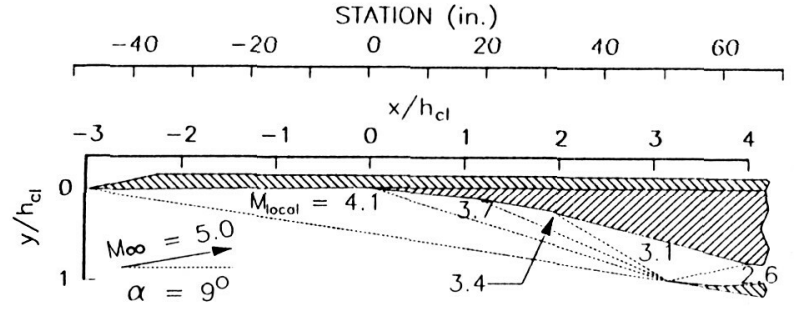

Figure 3: Inlet compression system to ramp shoulder

An inlet test program was planned for the Lewis Research Center $10 \mathrm{ft}$. by $10 \mathrm{ft}$. supersonic wind tunnel $(10 \times 10 \mathrm{SWT})$ as a result of the aircraft study. Only the lower (ramjet) portion of the dual flow duct was to be tested, representing supersonic flight between Mach 3 and 5 . The inlet for the over/under turbojet-ramjet propulsion system was designed inviscidly using the method of characteristics (MOC), with the compression surfaces adjusted to compensate for the viscous displacement effects as predicted by viscous boundary layer codes. The inlet employs four ramps and the cowl to provide the required external compression for operation at design (Mach 5) conditions. The fourth ramp angle is varied for offdesign operation. The oblique shocks generated by the ramps are designed to intersect very near the cowl lip, and the cowl shock is cancelled at the inlet shoulder. A cross-section showing the aerodynamic contours of the inlet to a station just aft of the shoulder is shown in Figure 3 . The $x$ - and $Y$-dimensions are nondimensionalized to the cowl lip height, $h_{c l}$. At cruise conditions, the freestream airflow is oriented at a $9^{\circ}$ angle relative to the first ramp surface. The wedge angles of the last three external ramps with reference to the first are $5^{\circ}, 10^{\circ}$, and $15^{\circ}$, respectively. The cowl lip provides an additional $5^{\circ}$ of turning. Oblique shock wave locations are indicated by the dashed lines. The local Mach numbers, predicted inviscidly, are shown for varlous regions in the flow fleld. Specifics of the inlet design are fully discussed in Reference 3.

The first three-dimensional computational fluid dynamics (CFD) calculation of the Mach 5 inlet flow fleld was accomplished by Benson (Reference 4) using a 3D parabolized Navier-Stokes (PNS) code which is discussed in Reference 5 . This analysis predicted a strong three-dimensional effect caused by the interaction of the ramp shock waves with the sidewall boundary layers. These interactions generated a vortical flow field within the sidewall boundary layer, which led to boundary layer separations downstream of the cowl leading edge. This effect is illustrated in Figure 4 , which shows predicted crosssectional total pressure contours at selected stations between the cowl lip and the shoulder. In this figure, the cowl surface is on top, with the ramp surface below. Each plane represents half of the inlet area at its respective station, with the left hand border of each cross-section being the centerline of the inlet. Massive separations such as that shown in the cowl corner would likely lead to an inlet unstart. The inlet model was later modified to include porous boundary layer bleed areas on the sidewalls in the vicinity of the shock-boundary layer interactions, and on the cowl in the corners near the leading edge and sidewalls, as shown in Figure 5 . This bleed was intended to control the threedimensional effects, and prevent separation on the cowl.

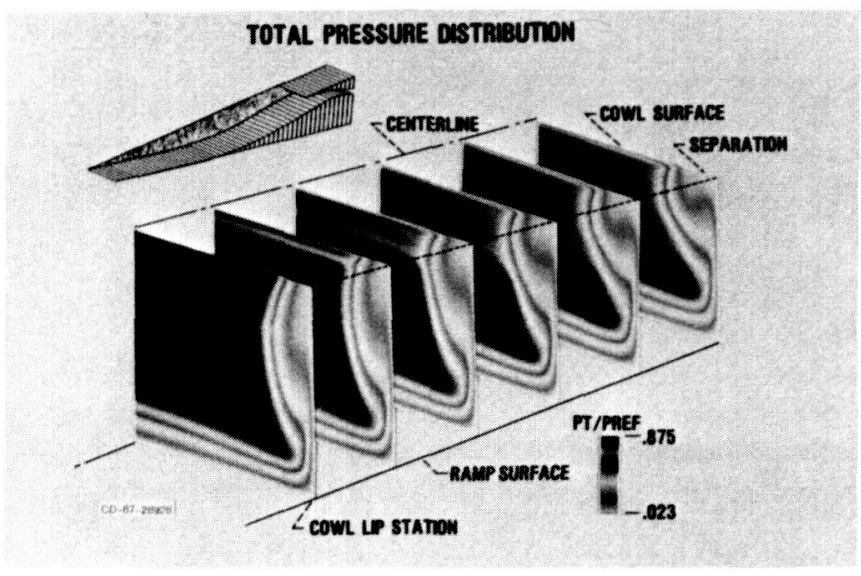

Figure 4: PNS analysis: total pressure contours at selected stations between the cowl lip and shoulder

As the development and use of hypersonic CFD codes grew, interest in the use of the Mach 5 inlet as a tool for code calibration and validation developed. The inlet, which was originally intended as a technology demonstrator, was modified to include additional instrumentation on the ramp and sidewalls in regions where 3-dimensional effects were predicted. Data from this instrumentation is now available to be used for comparison with analytical predictions. Data upstream of the inlet shoulder and some inftial CFD / data comparisons are to be presented in this paper. 


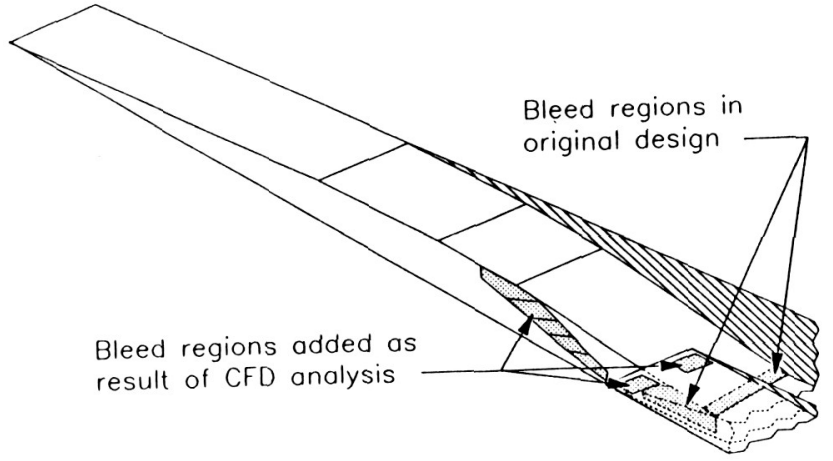

Figure 5: Bleed regions upstream of the ramp shoulder

\section{APPARATUS}

A photograph of the Mach 5 inlet, a $1 / 3$ scale model, Installed in the Lewis $10 \times 10$ SWT is shown in Figure 6. The inlet was mounted on a large trapezoidal plate. By actuating this "accelerator" plate to an $8.5^{\circ}$ negative angle of attack, the Mach 3.5 tunnel airflow was expanded to approximately Mach 4.1 on the inlet first ramp. This simulated the flow conditions present on the inlet first ramp when it is operating at Mach 5 flight conditions with the incoming airflow at an angle of attack of $9^{\circ}$, as previously indicated in Figure 3 . The first oblique shock was not reproduced, but the data was corrected for the loss that would occur across it. (Recovery across this initial oblique shock is 0.901.) The accelerator plate was 100 inches wide, the inlet capture height (with the first ramp at $0^{\circ}$ relative to freestream) was 16 inches, capture width was 16 inches, and the overall length of the model was 20 feet.

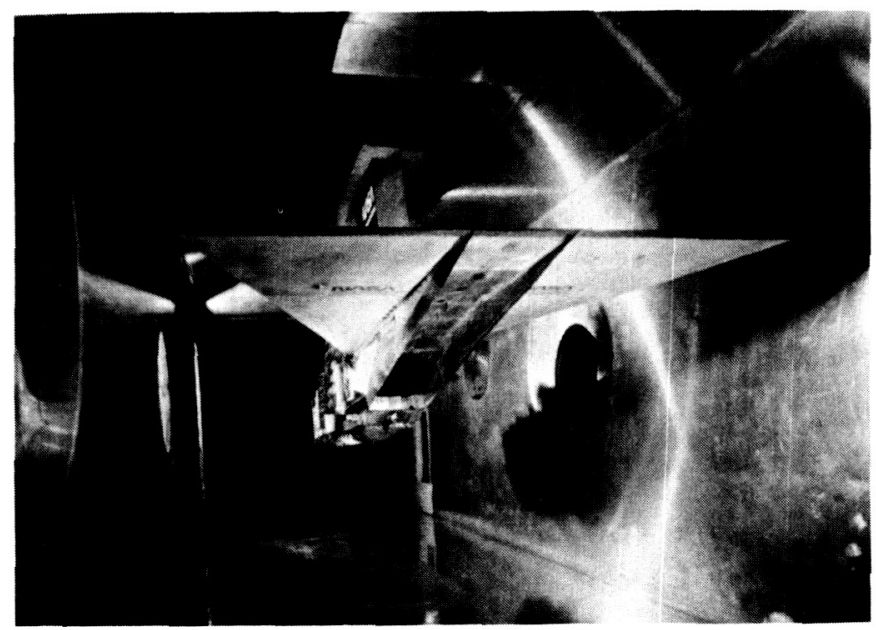

Figure 6: Mach 5 inlet model installed in Lewis Research Center $10 \mathrm{ft}$. by $10 \mathrm{ft}$. supersonic wind tunnel

The inlet made use of extensive variable geometry, including a collapsible ramp and remotely variable bleed exits on the ramp, cowl, and sidewalls. The flow through the upstream bleed regions shown earlier (in Figure 5) was changeable (between runs) by installing various sizes of flow restrictors in the exit ducts. (Ramp bleed flow from the region upstream of the shoulder shown in the sketch was remotely variable.) Variation in engine airflow was provided by a remotely actuated choked exit plug. Model instrumentation included surface static taps, fixed total pressure rakes, translating pressure probes, and dynamic pressure transducers. The locations of instrumentation upstream of the shoulder are presented in Figure 7 . Static taps on the ramp and cowl were located on the inlet centerline; and 4 inches, 6 inches, and 7.5 inches of $f$ the centerline. Static taps on the sidewalls were located in approximately vertical rows as shown. Eight boundary layer rakes on the ramp were located on the centerline and approximately 7.5 inches of $f$ the centerline. Translating pitot probes were located on all surfaces as indicated in the sketch. Four corner rakes, mounted to the cowl, were oriented in a $45^{\circ}$ angle between the cowl and sidewalls. A 0.5 inch strip of grit was applied near the leading edges of the ramp and sidewall to ensure that a fully turbulent boundary layer was ingested by the inlet.

\section{$\underline{\text { RESULTS }}$}

In Figures 8 - 30, experimental data for instrumentation upstream of the inlet shoulder are presented. For all data presented here, the tunnel freestream Mach number, $M_{0}$, is 3.49 ; and tunnel total pressure, $P_{0}$ is 35.1 psia (this is also total pressure on the first ramp, $P_{1}$.) The angle of attack of the accelerator plate, $a$, is $-8.55^{\circ}$, providing a Mach number on the 1st ramp, $M_{1}$, of 4.1. For all data, boundary layer bleed was removed from the ramp bleed region upstream of the shoulder. Bleed from this area removes approximately $0.5 \%$ of the total inlet capture mass flow. Data labeled "bleed" represents a configuration in which bleed was also removed from the regions on the sidewall and cowl shown in Figure 5 . This bleed represents approximately $8.8 \%$ of the capture mass flow.) A "no bleed" label indicates that porous bleed holes on the sidewalls and cowl were sealed.

Figures 8 and 9 show the static pressure distributions on the ramp for conditions both with and without bleed. Static pressure is nondimensionalized to total pressure on the inlet first ramp, $P_{1}$, and the station number is divided by the cowl lip height, $h_{c l}$. The locations of the cowl lip and shoulder are indicated by vertical dashed lines on the plot. Similarly, cowl static pressure distributions are shown in Figures 10 and 11 . For both of these sets of data, little difference between the bleed and no bleed configurations may be observed. Sidewall static pressure profiles for vertical rows of taps located at the stations indicated are shown in Pigures 12 - 14 . Figure 12 shows pressure distributions for the three most upstream rows of static taps. Since bleed and no bleed distributions were very simflar, only the bleed data are shown. Figures 13 and 14 show sidewall static pressure distributions at five stations further downstream for both bleed and no bleed configurations. The sidewall static pressure profiles do not seem to indicate the locations of oblique shocks from the ramps, except near the ramp in the cowl compression region. This is most likely due to the boundary layer flow migration on the walls caused by the sidewall / shock interactions.

Figures 15 - 19 show ramp boundary layer rake 


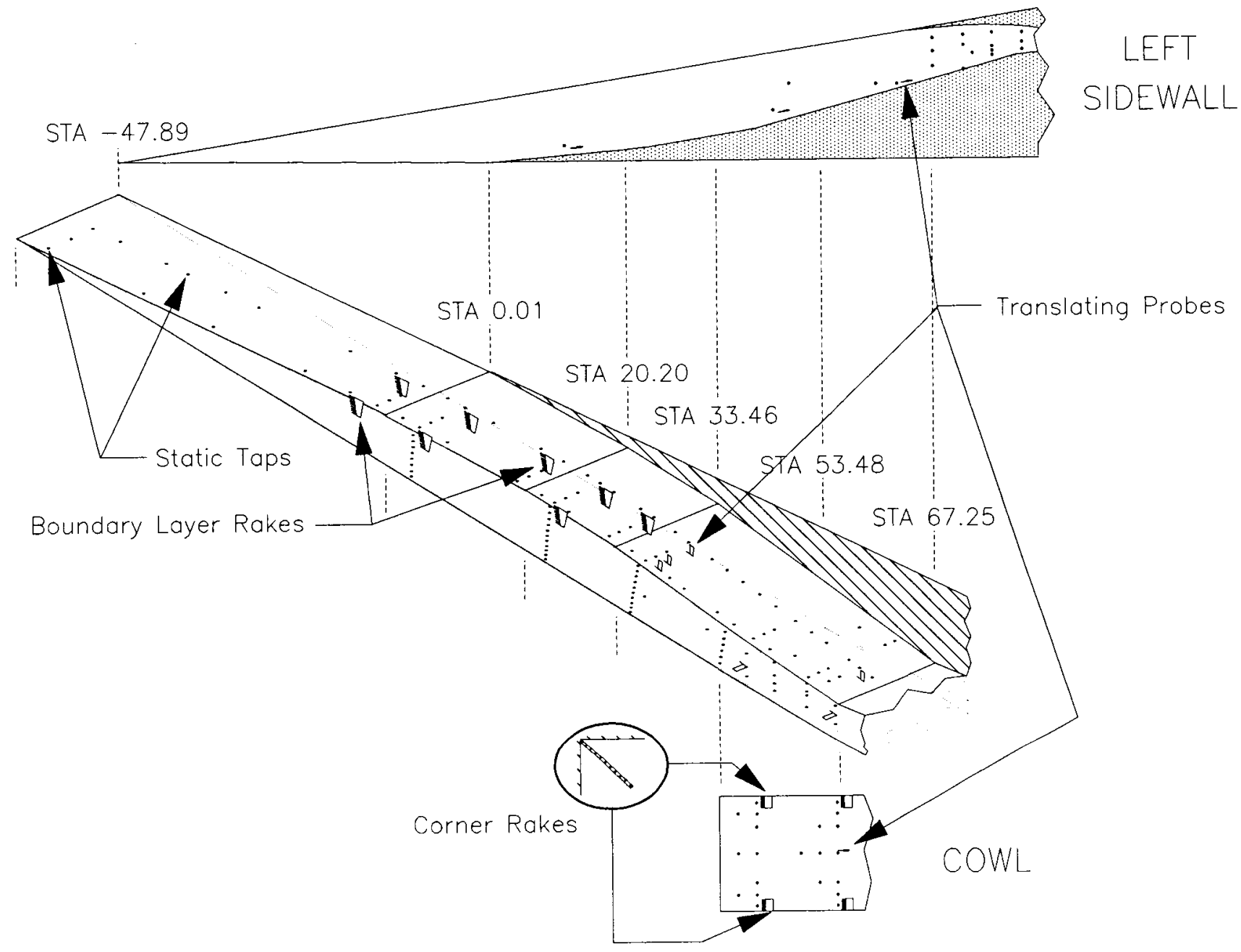

Pigure 7: Instrumentation upstream of inlet shoulder

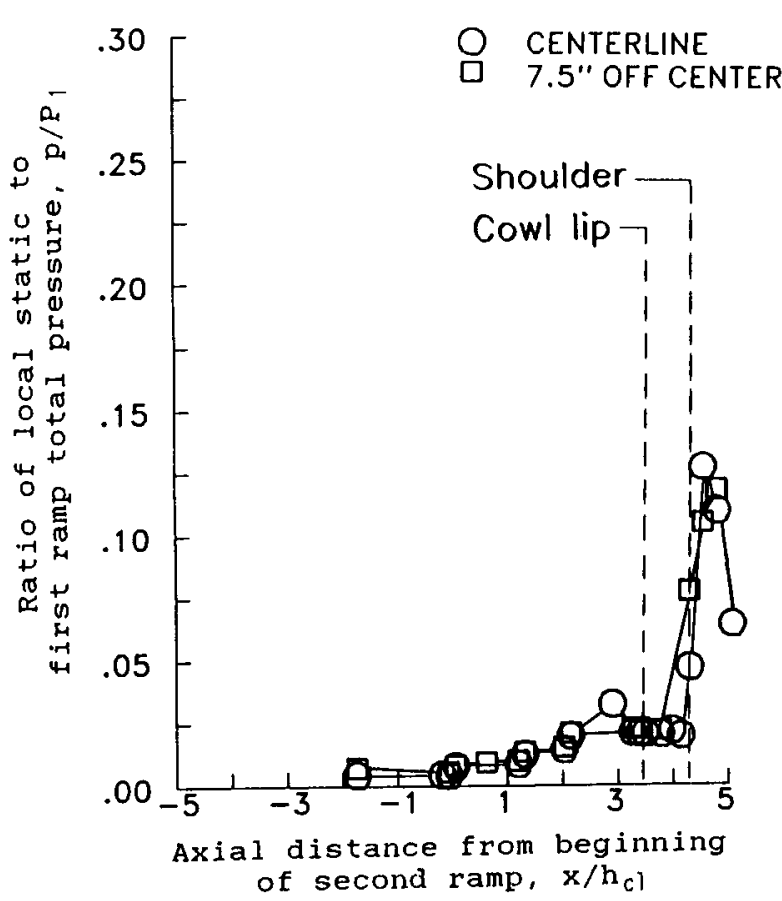

Figure 8: Ramp static pressure distribution: no bleed
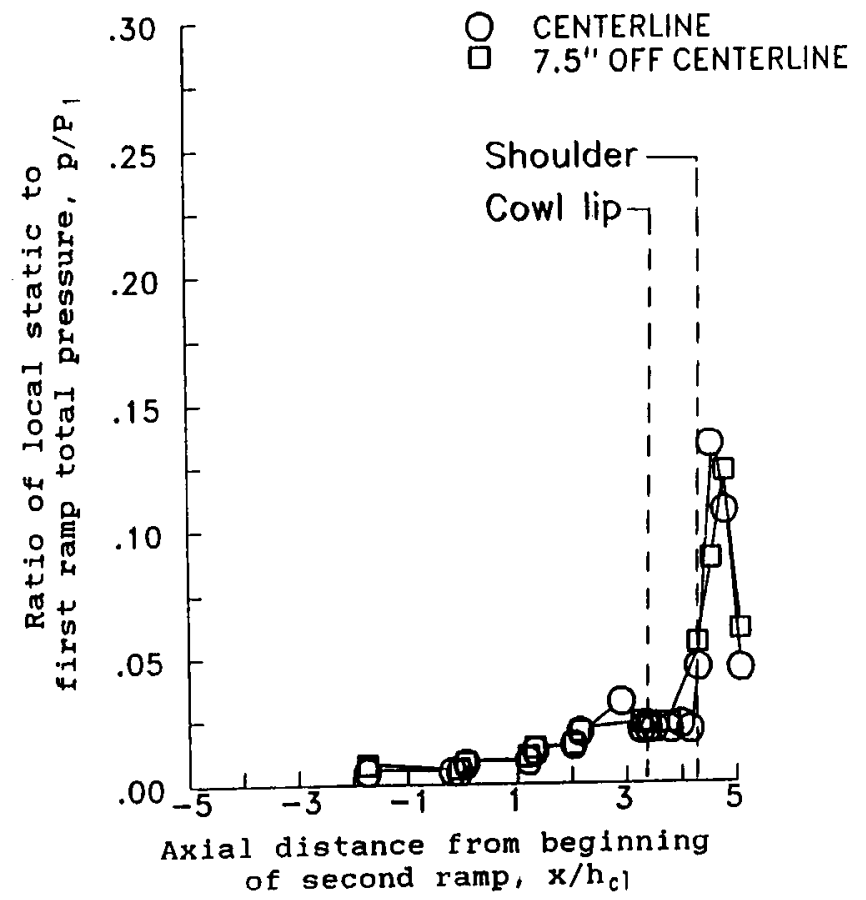

Figure 9: Ramp static pressure distribution: bleed 


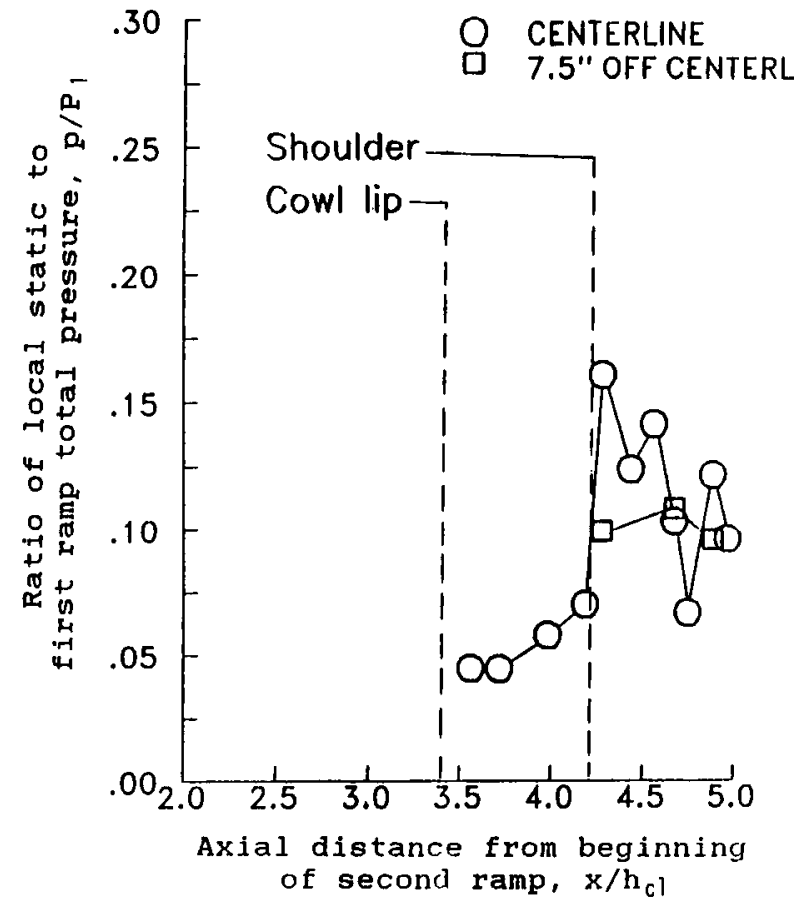

Figure 10: Cowl static pressure distribution: no bleed

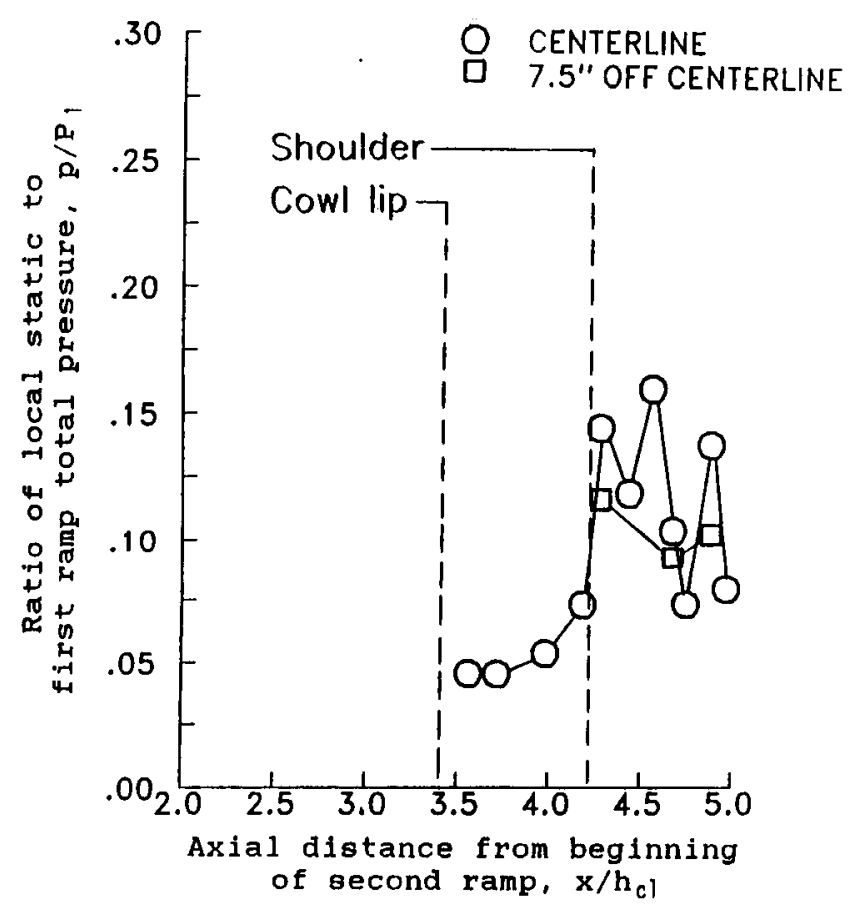

Pigure 11: Cowl static pressure distribution: bleed

profiles. Pitot pressure (nondimensionalized to $P_{1}$ ) is plotted vs. height from the ramp (nondimensionalized to $h_{c l}$ ). Higher pitot pressures generally indicate a lower supersonic local Mach number, except when the tube is located in the subsonic boundary layer. Circular symbols represent rakes located on the inlet centerline, and square symbols denote rakes located 0.5 inch away from the sidewall. The profiles obtained without bleed were

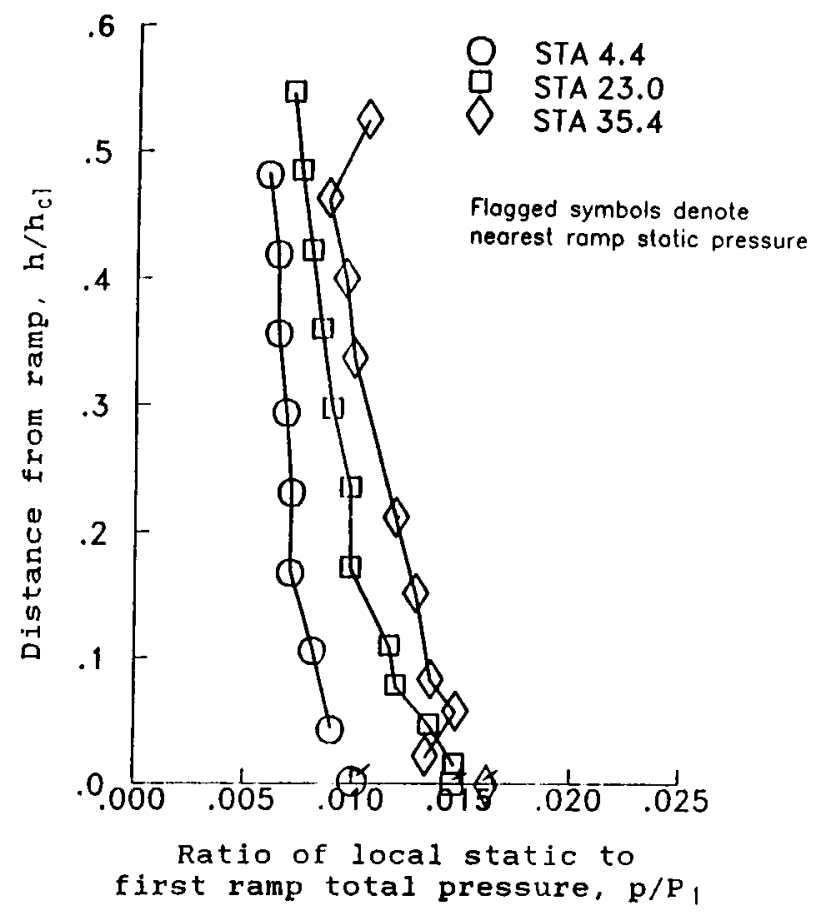

Figure 12: Sidewall static pressure distribution, stations $4.4,23,0$, and 35.4

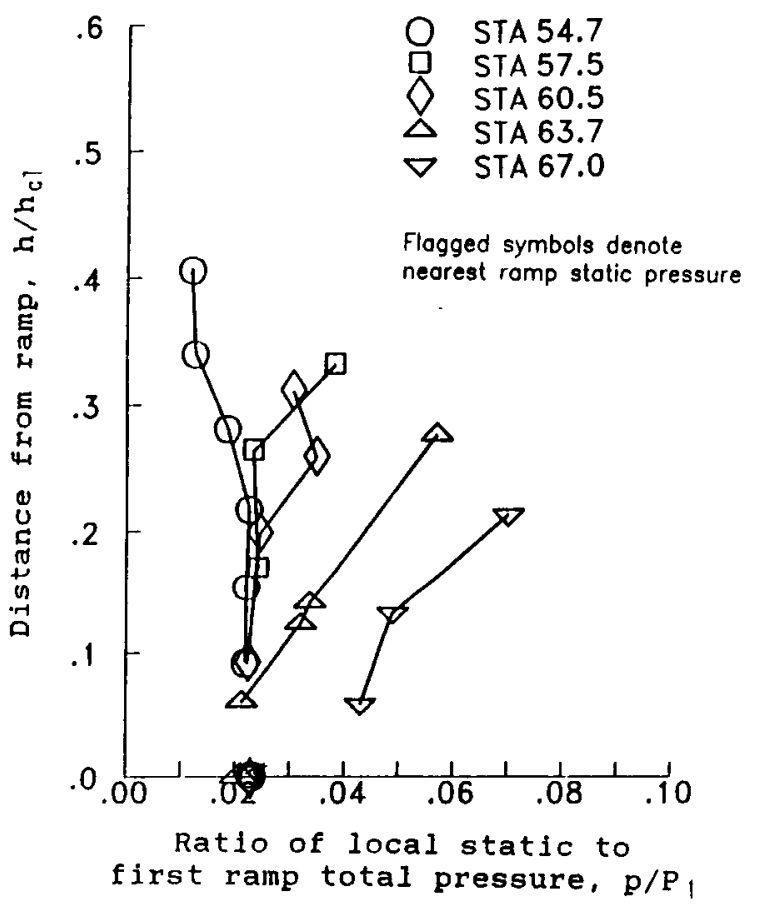

Figure 13: Sidewall static pressure distribution. stations 54.7, 57.5, 60.5, 63.7, and 67.0: no bleed

not significantly different from those with bleed, so only bleed data are shown. The first set of rakes, shown in Figure 15 , are located near the end of the first ramp. The next set (Figure 16) is located near the start of the second ramp. The drop in pitot pressure on the outermost tubes of the rake Indicates the location of the intersection of the oblique shock from the first ramp. A considerable 


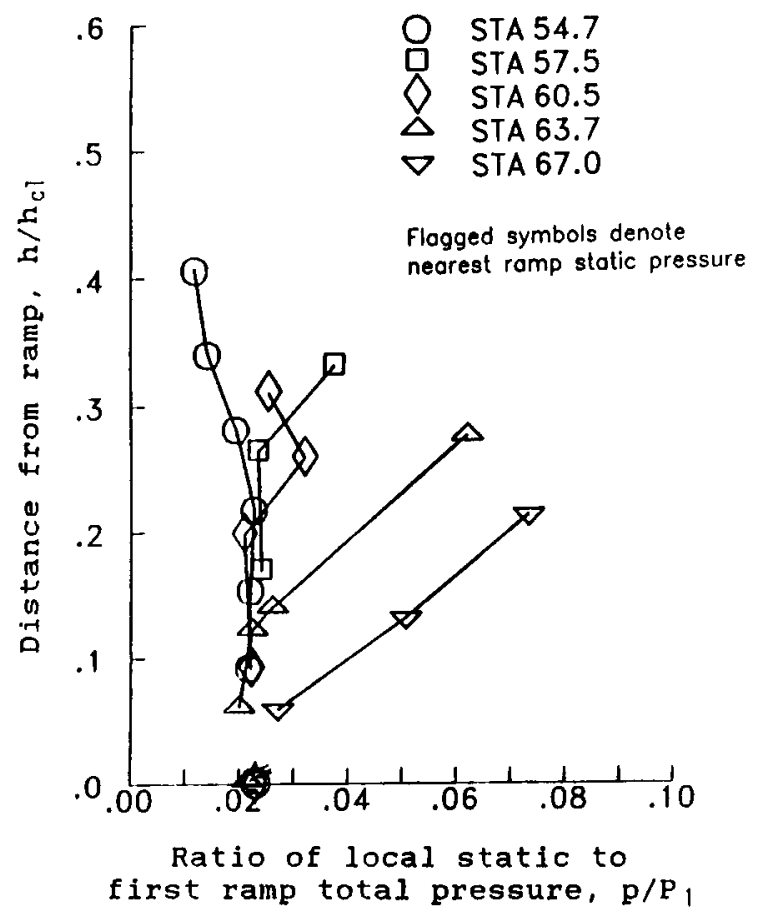

Pigure 14: Sidewall static pressure distribution, stations $54.7,57.5,60.5,63.7$, and 67.0: bleed

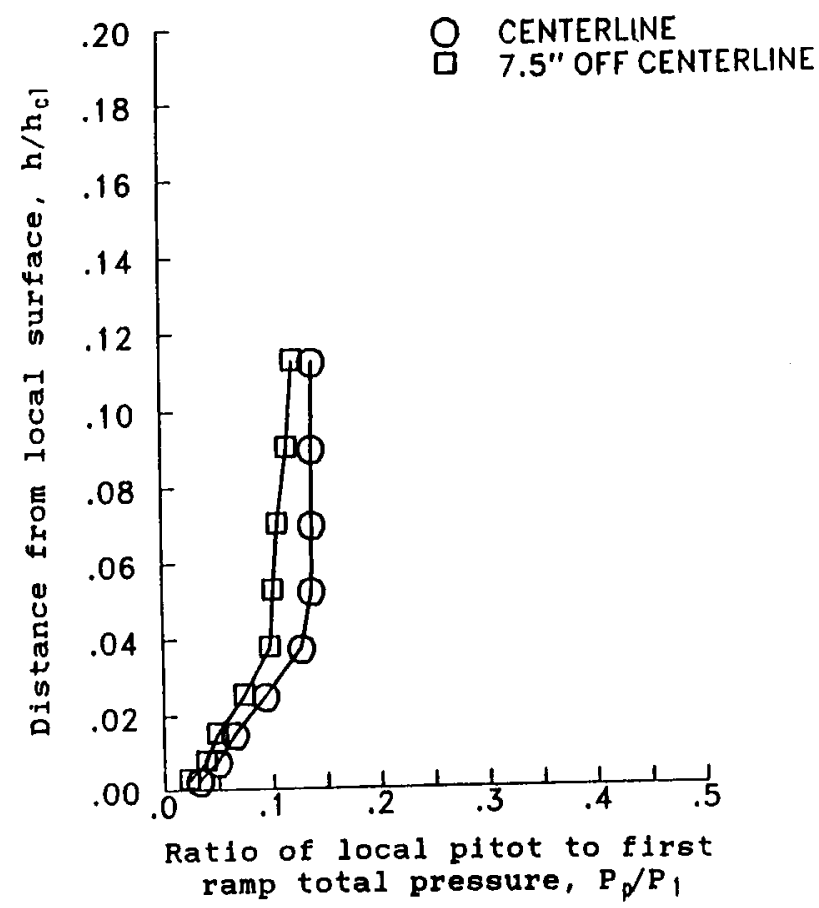

Flgure 15: Ramp boundary layer profiles, station $-3.0$

difference between the profile on the centerline and that near the wall can be seen at this station. Pigure 17 shows the pitot pressure profile on a rake located on the inlet centerline near the end of the second ramp, and Figure 18 shows rake profiles near the start of ramp 3 . Little difference

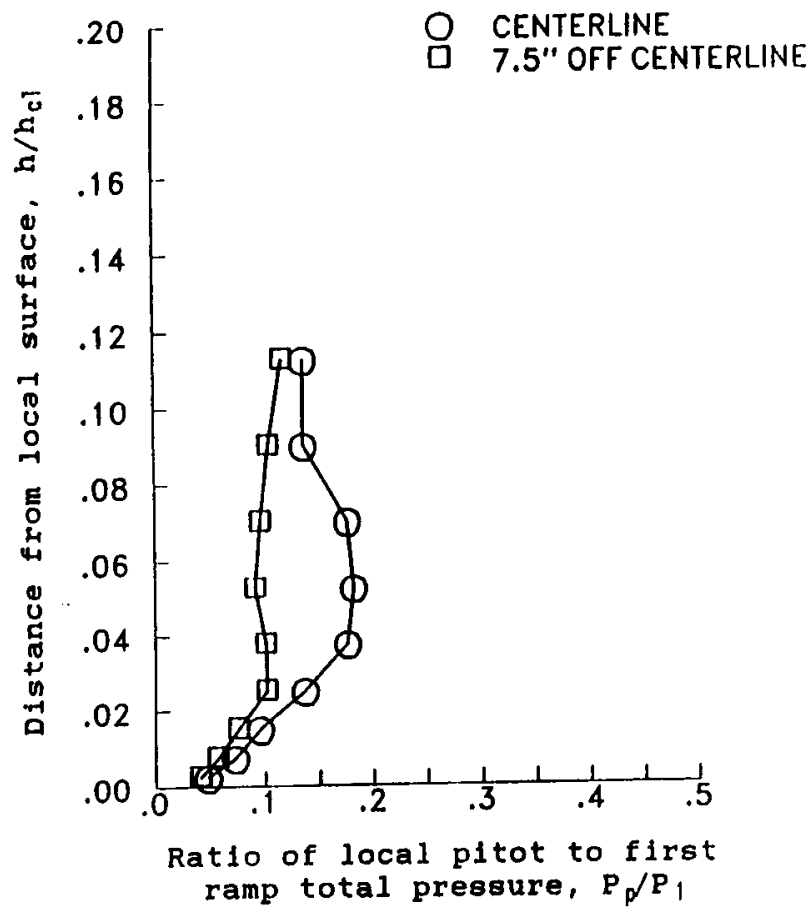

Pigure 16: Ramp boundary layer profiles, station 4.4

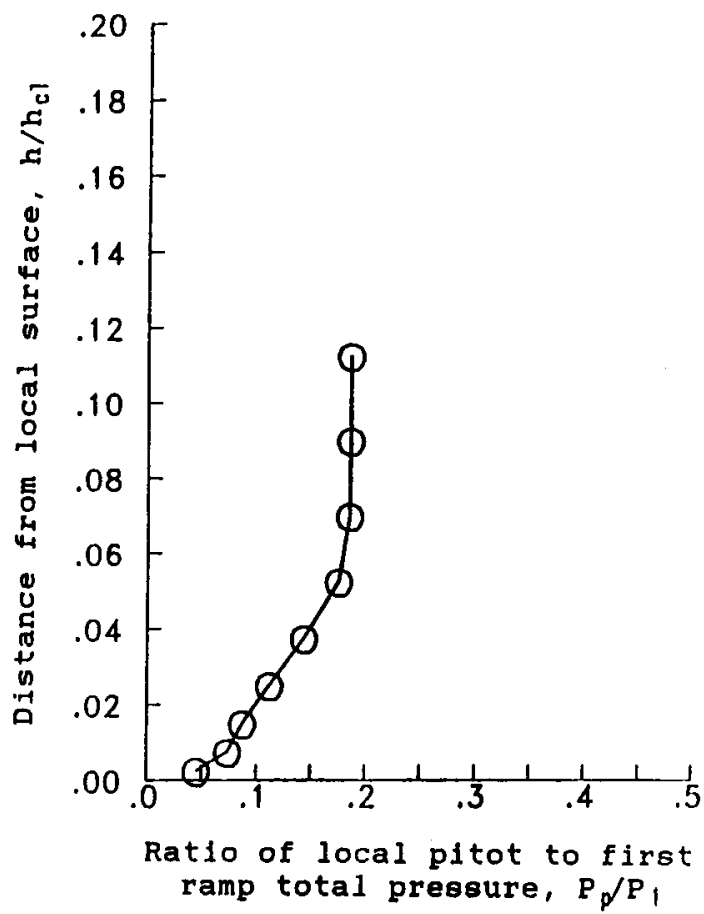

Pigure 17: Ramp boundary layer profile, station 17.2

between the near wall and centerline profiles is observed here. Figure 19 shows rake data near the end of the third ramp. All these rake profiles Indicate well developed boundary layer on the ramp. 


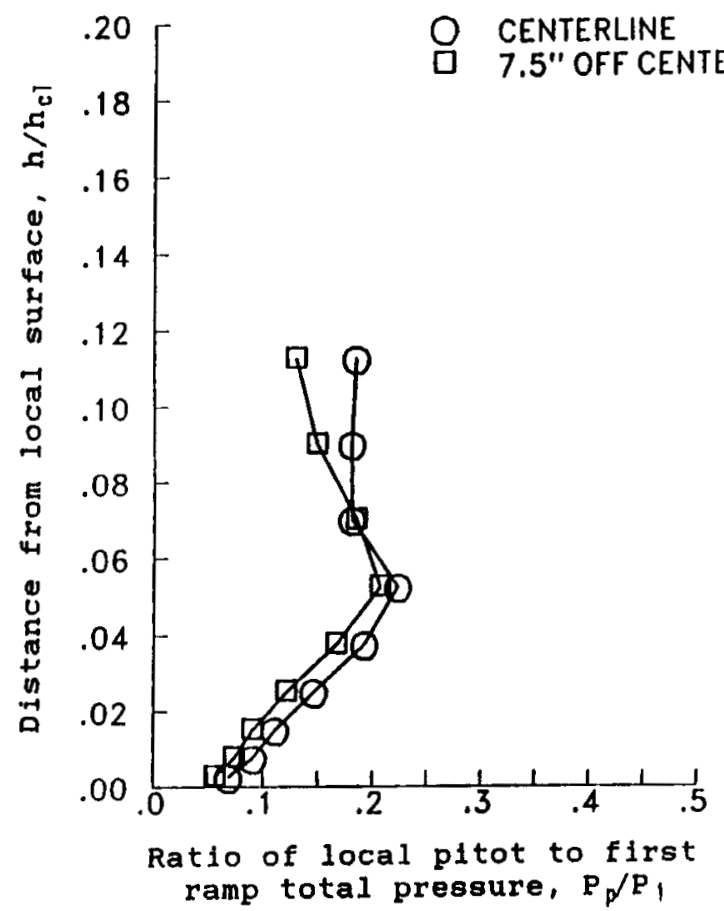

P1gure 18: Ramp boundary layer profiles, station 22.9

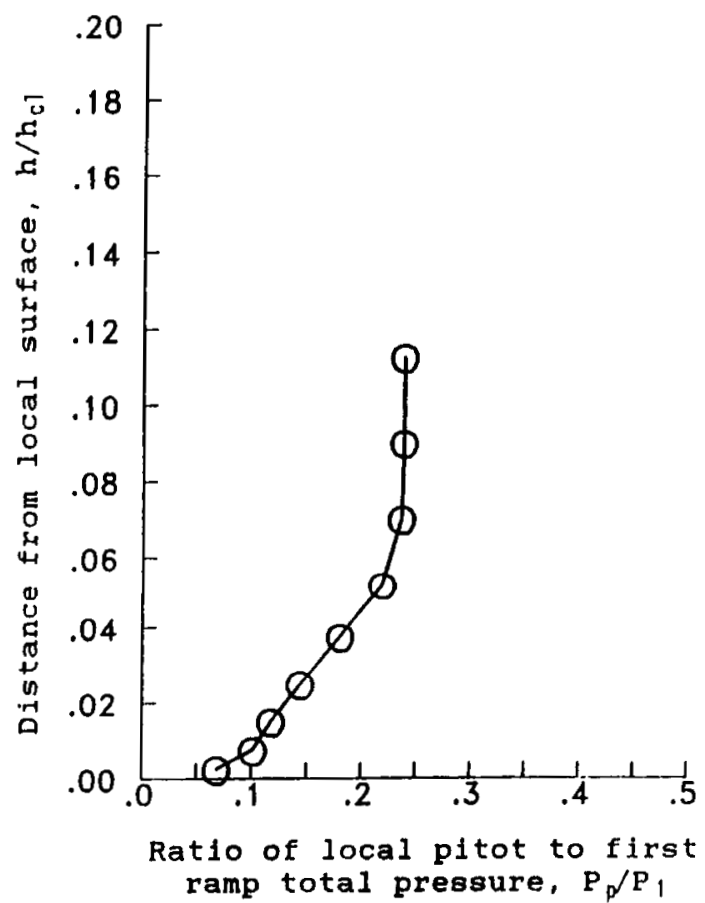

FIgure 19: Ramp boundary layer profile, station 30.5

In Figures 20 - 28, pitot pressure (nondimenslonalized to $P_{1}$ ) profiles are shown for translating probes at various locations in the inlet. Distances from the local flow surfaces are nondimenslonalized to $h_{c l}$. Where probes are located downstream of bleed areas, both bleed and no blced profiles are presented, with (with the exception of Pigures 21 \& 22) c1rcular symbols representing no bleed and squares denoting bleed configurations, respectively. Figure 20 shows survey data for a probe translating

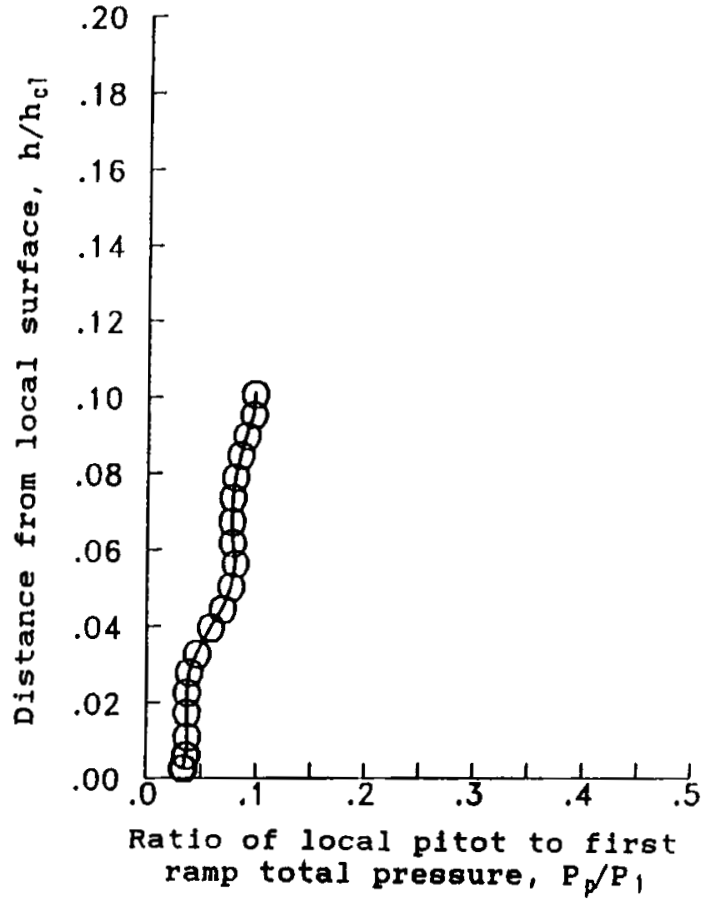

F1gure 20: Sidewall boundary layer profile, station 10.0: bleed

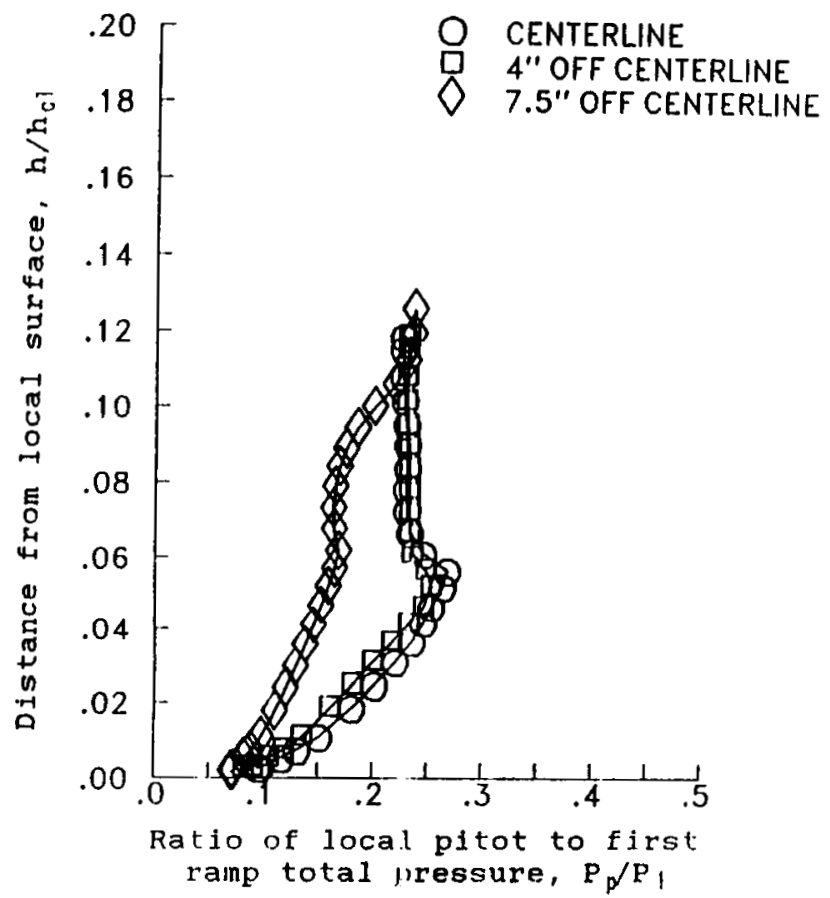

F1gure 21: Ramp boundary layer profiles, station 35.5: no bleed

out of the sidewall which is located at a station approximately 10 inches downstream of the start of the second ramp, and 1.1 inches above the ramp surface (5.6 inches aft of the rakes shown in Figure 16 and the first row of statics in Figure 12.) Pigures 21 and 22 show sidewall probes which extend down from the fourth ramp at a location just downstream of 1 ts leading edge. Figure 21 shows the no-bleed case, and Figure 22 the bleed case. The circles represent the probe located on the centerline; the squares indicate 


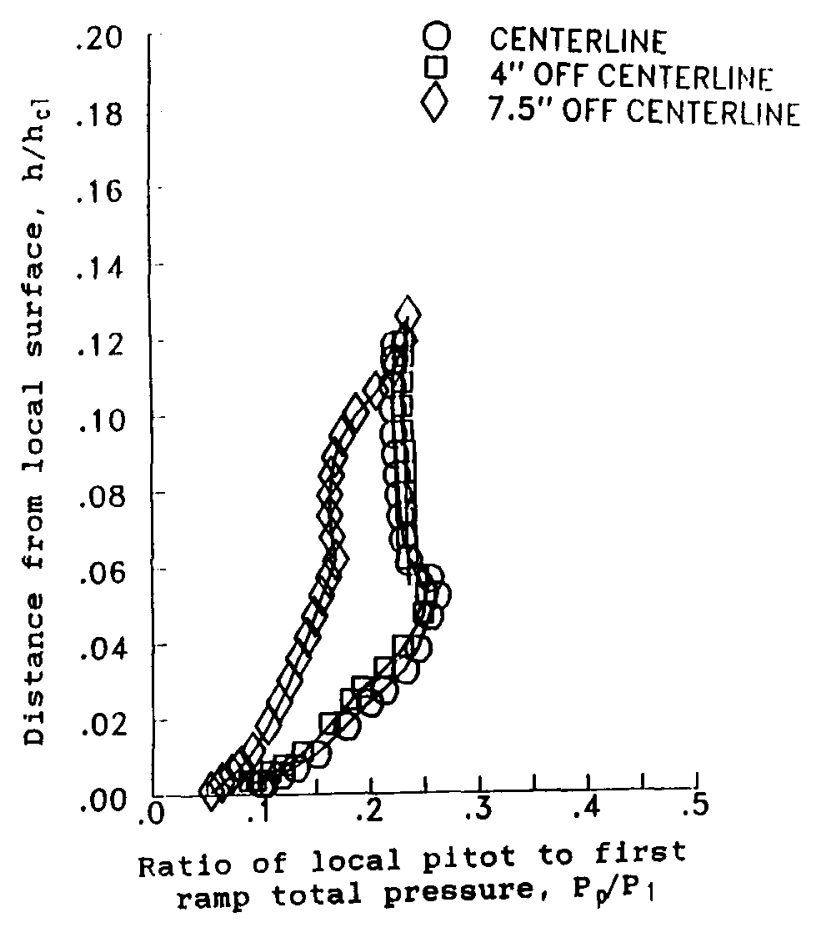

FIgure 22: Ramp boundary layer profiles, station 35.5: bleed

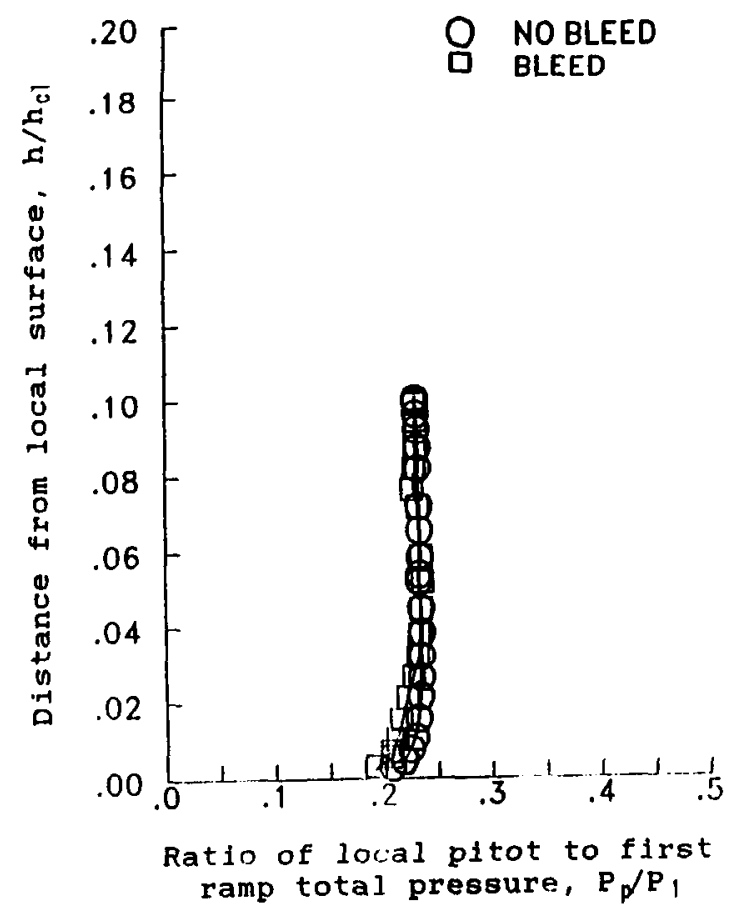

Flgure 23: Sidewall boundary layer profile, station 35.4

the probe situated 4 inches off the centerline; and the diamonds denote the probe located 0.5 inches off the sidewall. The drop in pitot pressure approximately halfway up the survey indicates the location of the intersection of the oblique shock from the fourth ramp. Flgure 23 shows the survey data for a probe which extends out fron the sidewall at station 35.4 (corresponding to the three probes shown in the previous two figures and the third row

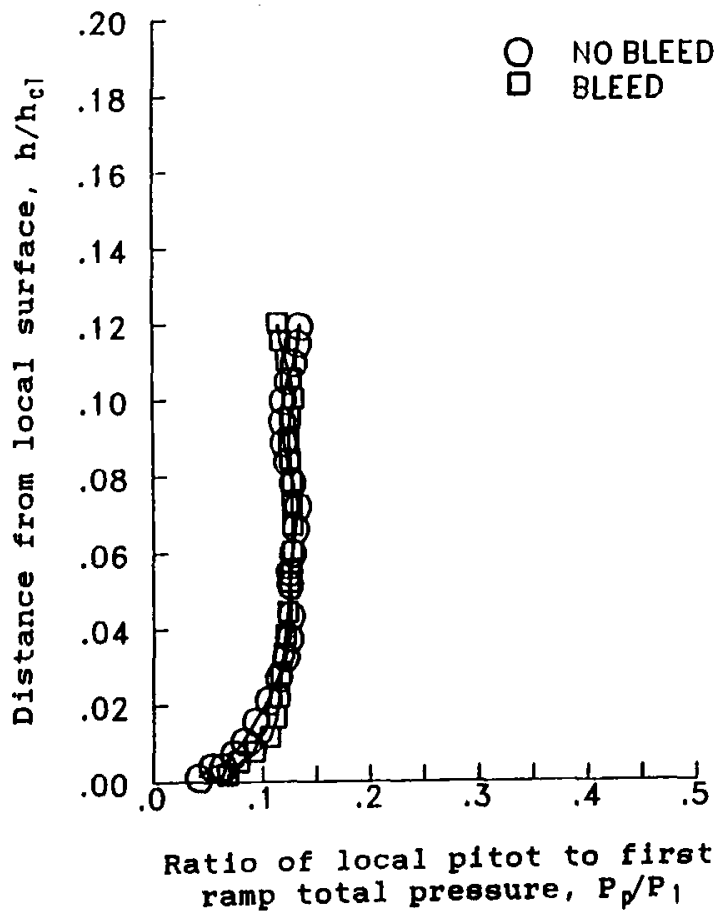

F1gure 24: Sidewall boundary layer profile, station 52.3

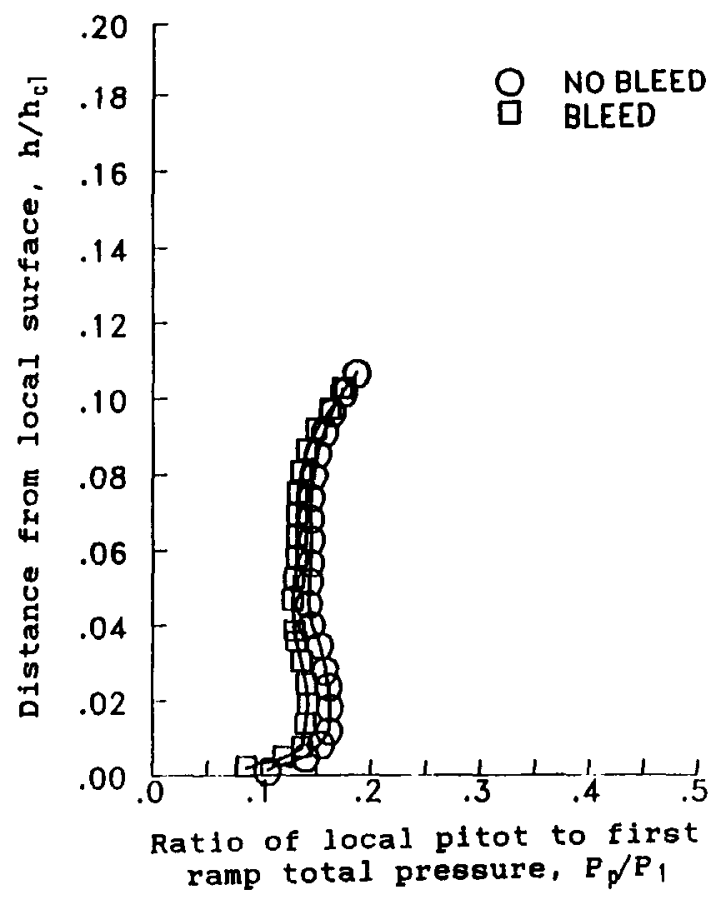

PIgure 25: Sidewall boundary layer profile, station 57.0

of sidewall statics presented in Pigure 12), located approximately 1.7 inches from the local ramp surface. The probe presented in Figure 24 is also located on the sidewall at station 52.3 (Just upstream of the first row of statics shown in Figure 14), and about 3.3 inches from the ramp. The sidewall probe from which the survey in Figure 25 is recorded is located approximately at the sane station as the row of sidewall stat $1 \mathrm{cs}$ denoted by squares in $\mathrm{FIgure} 14$, and is 7 inches from the local ramp surface. 


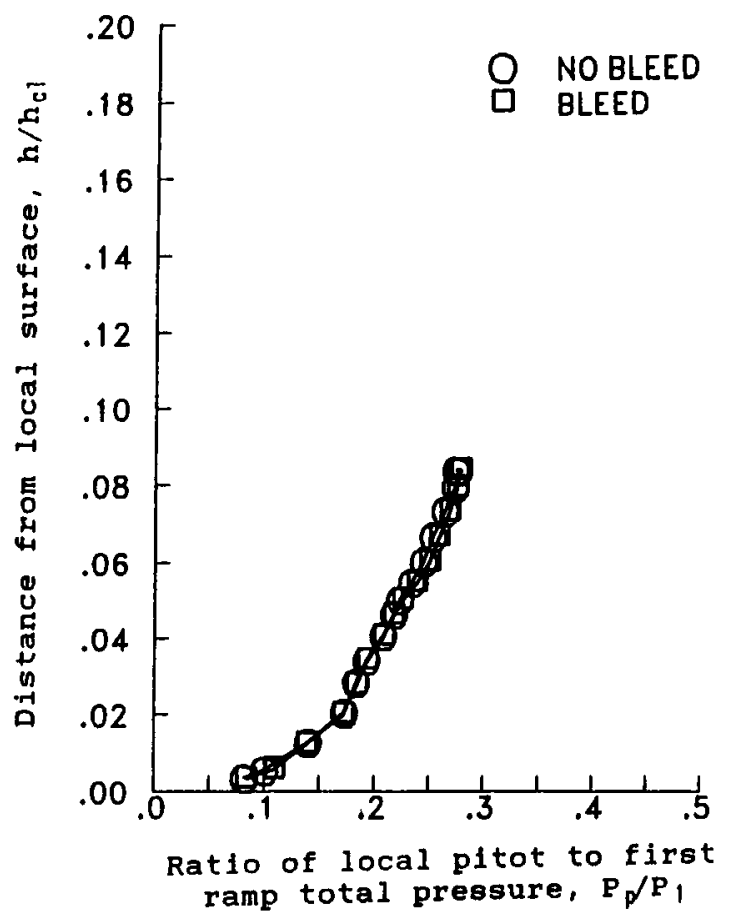

F1gure 26: Ramp boundary layer profile, station 62.5

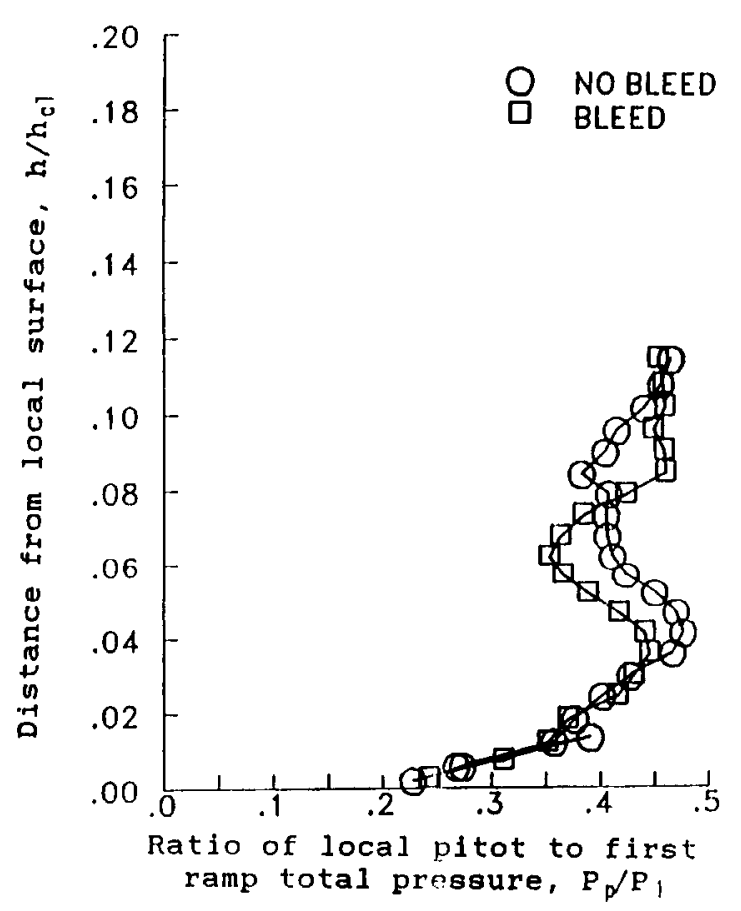

FIgure 27: Sidewall boundary layer profile, station 63.8

The probe of Pigure 26 is located on the ramp centerline at station 62.5. The sidewall probe in Figure 27 is at approximately the same station, and 6 inches from the ramp surface. This station corresponds to the row of sidewall statics denoted by right-81de-up triangles in Figure 14. The probe of Figure 28 is located slightly aft of these, at station 68.5 (near the row of sidewall statics

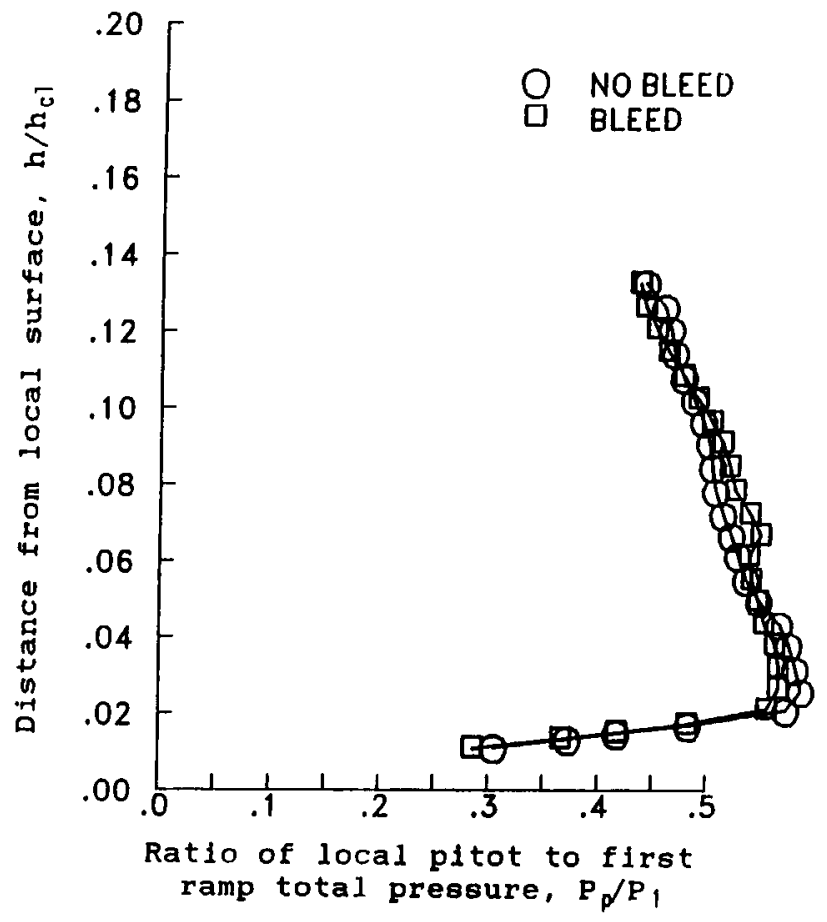

Figure 28: Cowl boundary layer profile, station 68.5

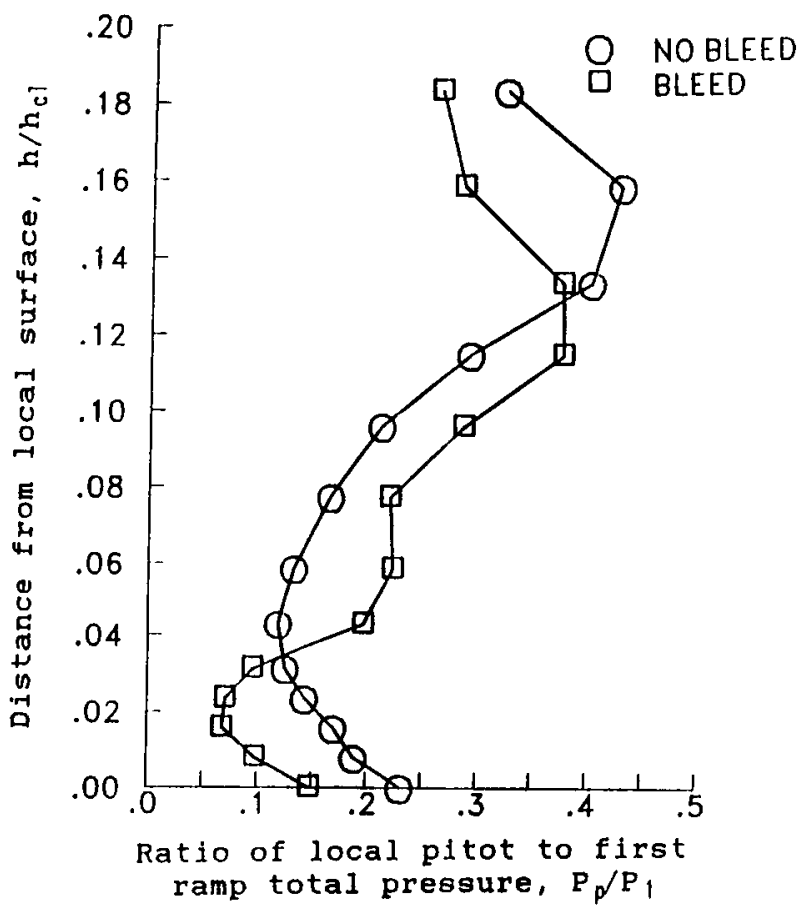

Blgure 29: Cowl corner rake profiles, station 59.6

represented by right-side-down triangles), on the cowl centerline, and it extends up into the flow towards the ramp. In general, bleed and no bleed profiles for the probes downstrean of the cowl lip are similar, with the exception of those for the probe of Bigure 27 .

In Pigures 29 and 30 , pitot pressure profiles are presented for cowl corner rakes located at stations 59.6 and 68.5 inches, respectively. These 


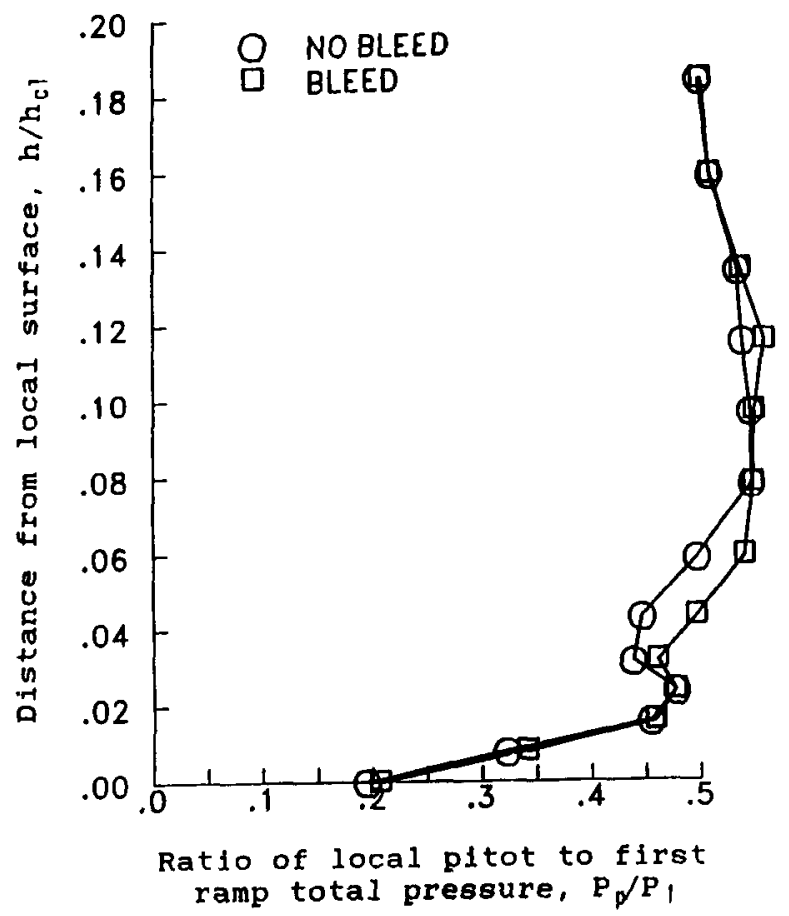

P1gure 30: Cowl corner rake proflles, station 68.5

rakes cut across the 3D corner vortical flow region predicted by CFD analyses. Station 59.6 is approximately 6.1 inches aft of the cowl lip. For the no bleed configuration, at this station, great changes in pressure are observed, with a region of medium pitot pressure very near the corner, which decreases rapidly, and then rises with a decrease near the end of the rake. With bleed, the profile shows an additional small rise in pitot pressure after the Initial fall-off, and the pressure near the end of the rake falls of $f$ sooner. At station 68.5, which is about 15 inches aft of the cowl lip, there is only a small "bump" in the profile near the corner. Bleed and no bleed profiles are simflar at this station. The data for this profile would tend to Indicate that the vortical flow action is not present at this location (either it has moved toward the center of the flow or disappeared at this station.)

\section{CFD / DATA COMPARISONS}

Rose (Reference 6) calculated the flow field in the Mach 5 inlet using the Kumar explicit, timeaccurate implementation of MacCormack's algorithm for solving the full Navier-stokes equations. This calculation begins at the start of the second ramp; however, the incoming boundary layer (assumed to be turbulent) is accounted for by including in the incoming flow a boundary layer profile calculated for Mach 4.1 flow on the first ramp. The leading edge of the sidewalls begins at the start of the second ramp as well. The code assumes turbulent boundary layer on all surfaces from the start of their respective leading edges. For the comparisons shown here, bleed 18 removed in two places: $4 \%$ of the capture mass flow is removed from the ramp in the vicinity of the shoulder, and 3\% is removed from the cowl through notches 3 inches wide on either side of the cowl and extending back 6 inches from the leading edge (not a configuration specifically tested.)

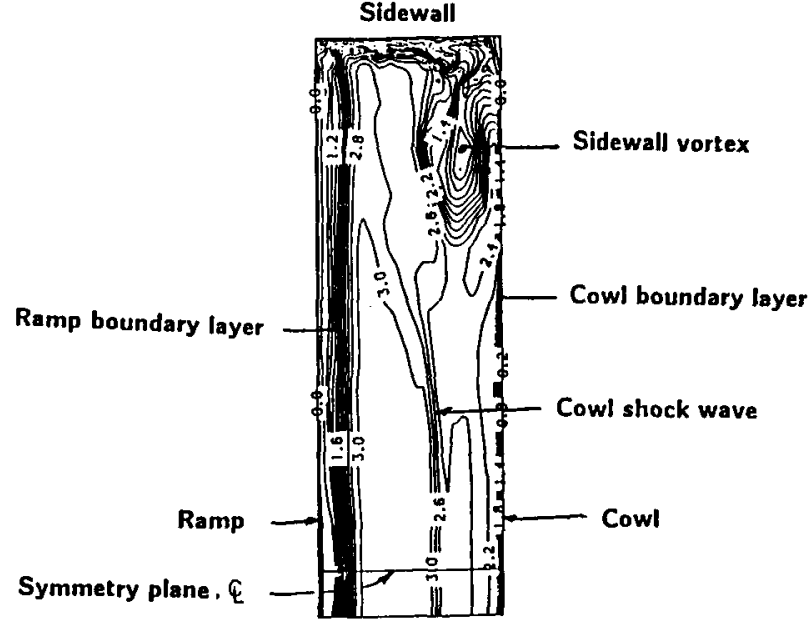

F1gure 31: Rose FNS analysis: Nach number contours at a cross plane near the inlet shoulder

Pigure 31 shows Rose's predicted airflow conditions for one-half of a cross-section of the inlet. This cross-section 18 between the cowl lip and shoulder axial stations. The cowl surface is to the right and the ramp surface is to the left. The inlet centerline is indicated near the bottom of the section, and the sidewall 18 at the top. The Mach number contours show a separation similar to that predicted by Benson's PNS analysis shown in Pigure 4, despite the boundary layer bleed removed from the cowl.

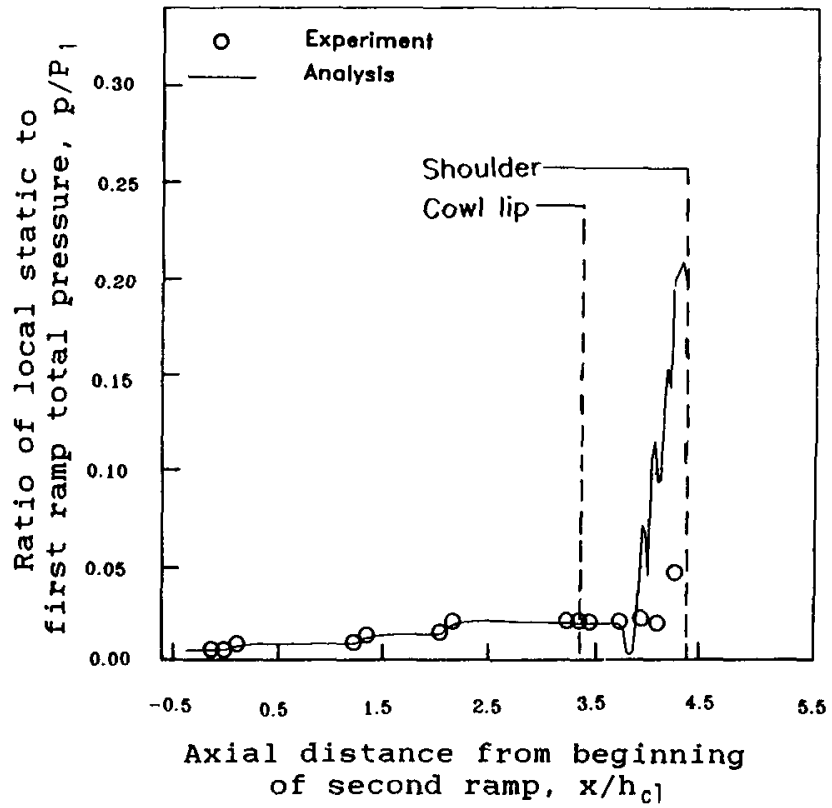

P1gure 32: Rose FNS analysis / data comparison: ramp centerline static pressure

Pigures 32 and 33 show analysis / data comparisons for centerline static pressures on the ramp and cowl. Code / data agreement is reasonable, except on the ramp near the start of the ramp bleed region. The discrepancy may be due to differing amounts of bleed between the experiment and analysis. 


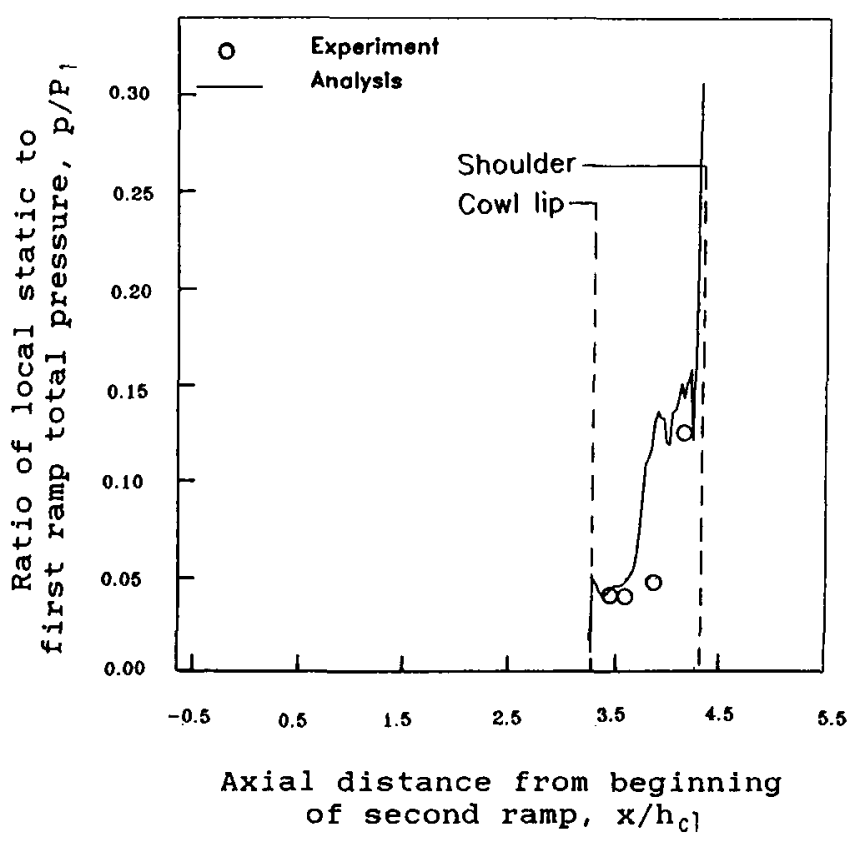

Pigure 33: Rose FNS analysis / data comparison: cowl centerline static pressure

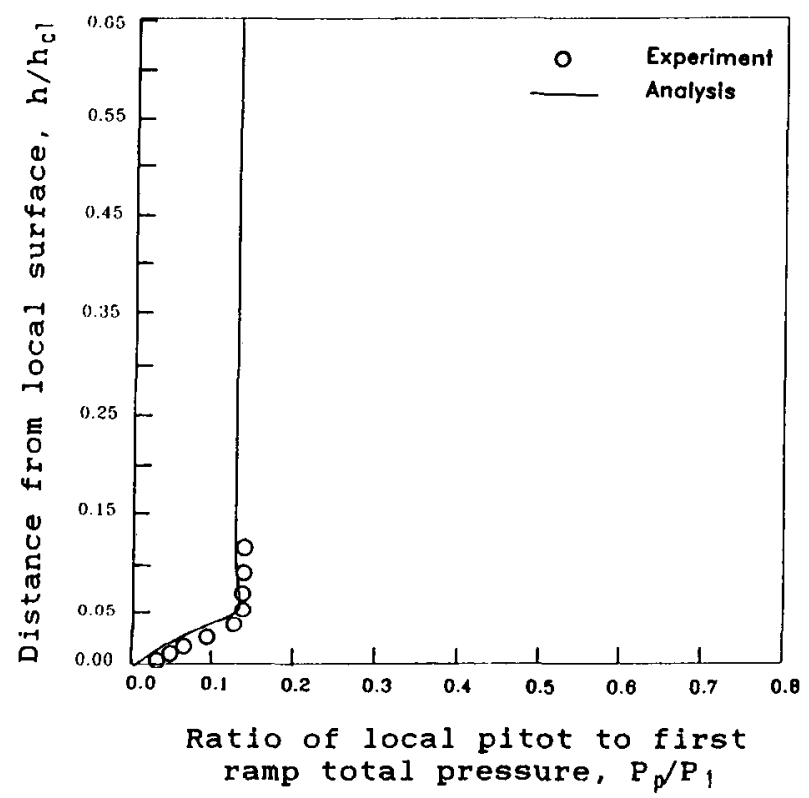

Pigure 34: Rose FNS analysis / data comparison: ramp centerline boundary layer profile, station -3.0

Pigures 34 - 36 show comparisons of boundary layer profiles on the inlet centerline at the end of the first, second and third ramps, respectively. Pitot pressures are nondimensionalized to $P_{1}$, and the distance from the ramp surface is divided by $h_{c l}$. In Figures 35 and 36 , the locations of the oblique shock intersections through the measurement plane can be observed in the analysis, which extends much further out from the ramp than does the actual rake. These three comparisons indicate that in flow areas where three-dimensional effects are negligible, the analysis agrees closely with the data.

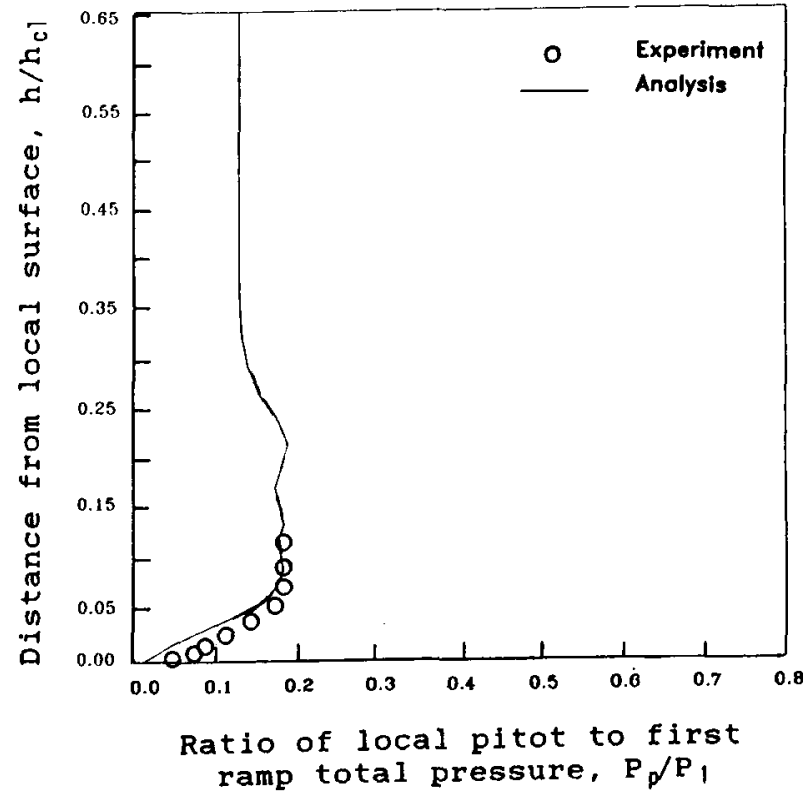

FIgure 35: Rose FNS analysis / data comparison: ramp boundary layer profile, station 17.2

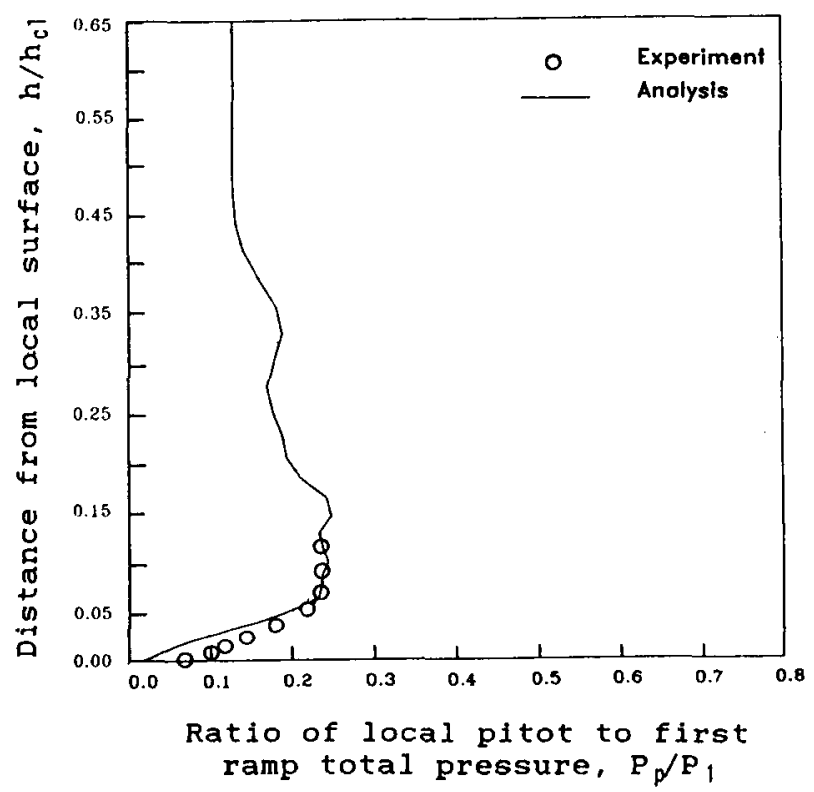

Pigure 36 : Rose FNS analys 1 s / data comparison: ramp boundary layer profile, station 30.5

Figure 37 compares the analytical prediction of the corner rake profile at station 59.6 (6" aft of the cowl lip) to data from that rake. The circular symbols represent no bleed data, and the squares denote bleed data. The shape of the bleed profile is similar to the analysis; however, the pitot pressures for the analysis are generally lower. This difference may be due to the shorter length of the sidewalls (generating less boundary layer) than those of the actual inlet. 


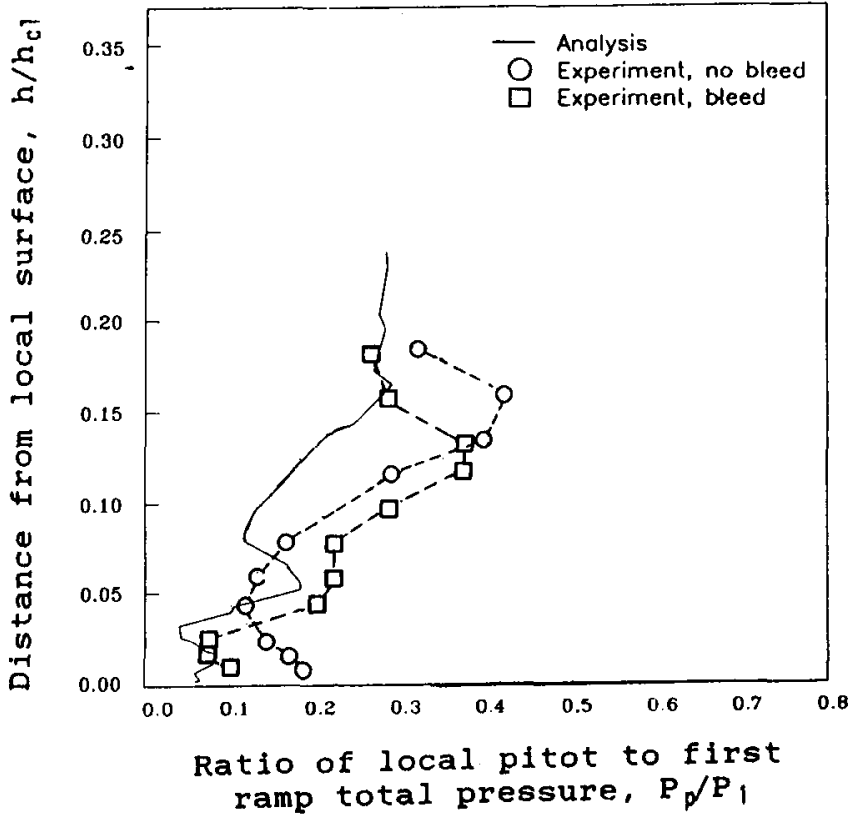

Figure 37: Rose FNS analysis / data comparison: Cowl corner rake profile, station 59.6

Recently, analyses of the Mach 5 inlet have been completed using a three-dimensional, full NavierStokes time-marching code. The PARC3D code, described in Reference 7 , solves the full threedimensional Reynolds-averaged Navier-Stokes equations in strong conservation form with the Bean and Warming approximate factorization. The turbulence model used in the code for this study is the Baldwin-Lomax model. The solution presented here assumes no bleed $f$ low is removed from the inlet on any surface.

Figure 38 shows Mach number contours in cross planes at selected axial stations. The figure shows the interaction of the shocks with the boundary layer on the sidewalls. The strong secondary flow set up by this shock/boundary layer interaction and the migration of the low energy fluid towards the center plane of the inlet as the flow approaches the throat region can be seen.

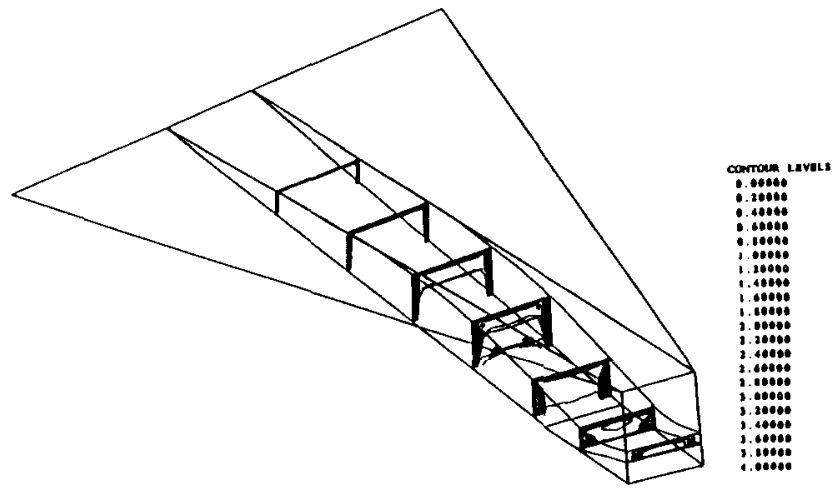

PIgure 38: PARC3D FNS analysis: Mach number contours at selected axial stations
A comparison of the predicted static pressures along the ramp centerline with the experimental data is shown in Figure 39 . In this and the following figures, pressures are nondimensionalized to ranp 1 total pressure, $P_{1}$, and heights and distances are divided by cowl lip height, $h_{c l}$. The agreement of the solution with the data is reasonable in the region upstream of the ramp bleed area. The comparison aft of that differs due to the absence of bleed in the analysis. Figure 40 shows a similar comparison for the cowl centerline.

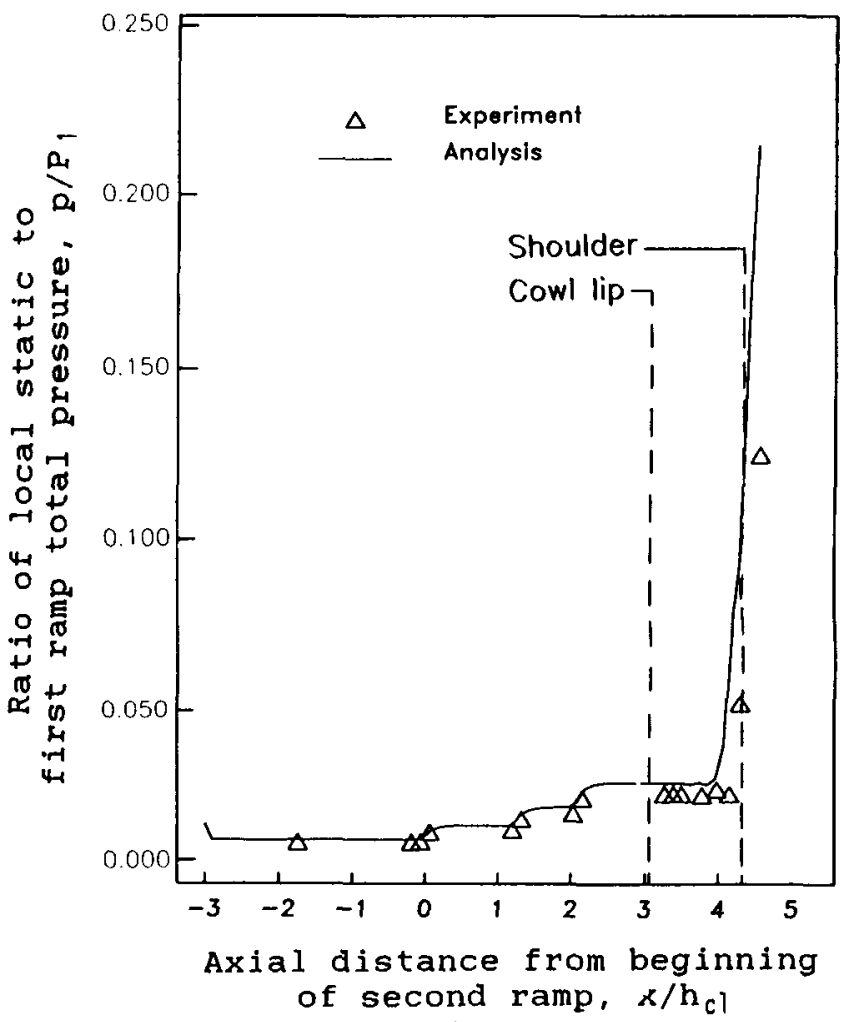

Pigure 39: PARC3D analys is / data comparison: Kamp centerline static pressure

Pitot pressure prof 11 es are compared at locations along the ramp centerline in Figures $41-43$. The agreement of the solution with the data is reasonably good. Figure 41 shows the profile for a rake near the end of the first ramp, and Pigure 42 shows the profile corresponding to a rake located near the end of the second ramp. For both comparisons (though to a lesser extent for the first,) The computed maximum pitot pressure is slightly larger than the measured value. This disagreement is attributed to a slightly lower Mach number of the calculated flow approaching the rake. This lower Mach number is the result of a weak compression wave generated due to the boundary layer growth on the sidewall at the entrance of the inlet. This phenomenon does not seem to be present in the experinental data. The pitot pressure profile for a rake located near the end of the third ramp is shown in Figure 43 along with the experimental data. Once again for the reasons mentioned previously, the maximun computed values are slightly larger than the measured values in the two-dimensional region of the flow.

Pigure 44 shows a comparison of the predicted p1tot pressure profile of the corner rake located 6 inches aft of the cowl leading edge with bleed and no 


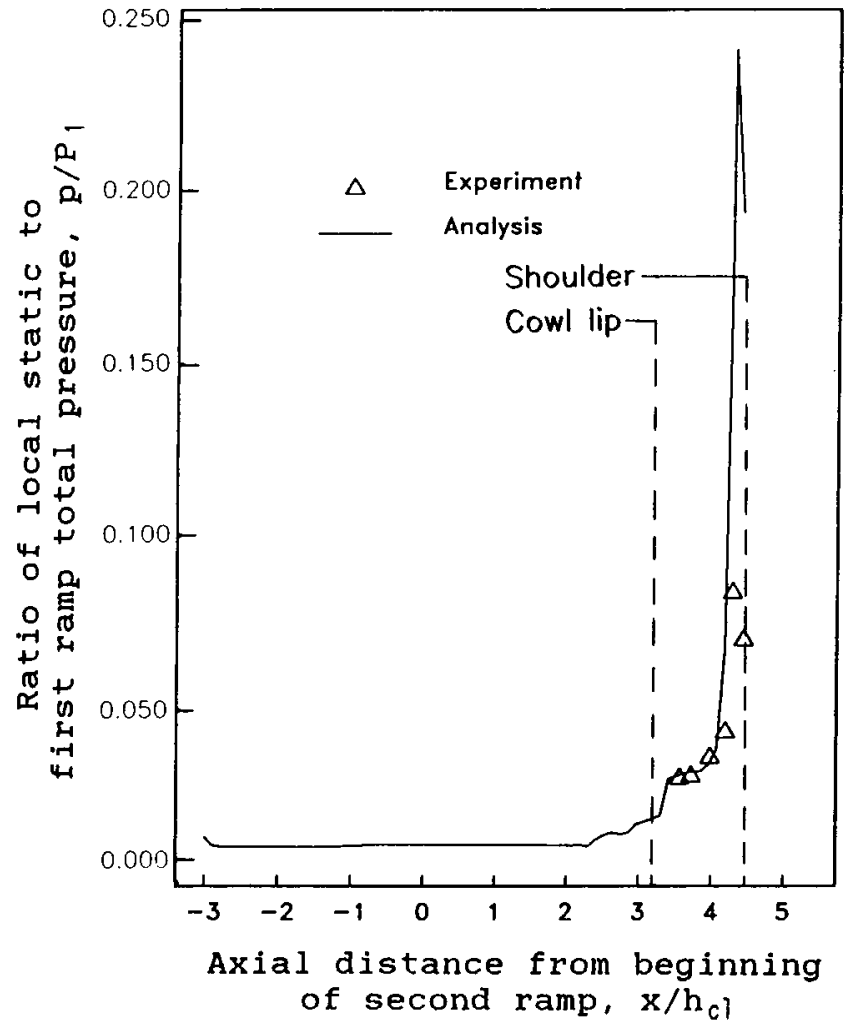

F1gure 40: PARC3D analysis / data comparison: cowl centerline static pressure

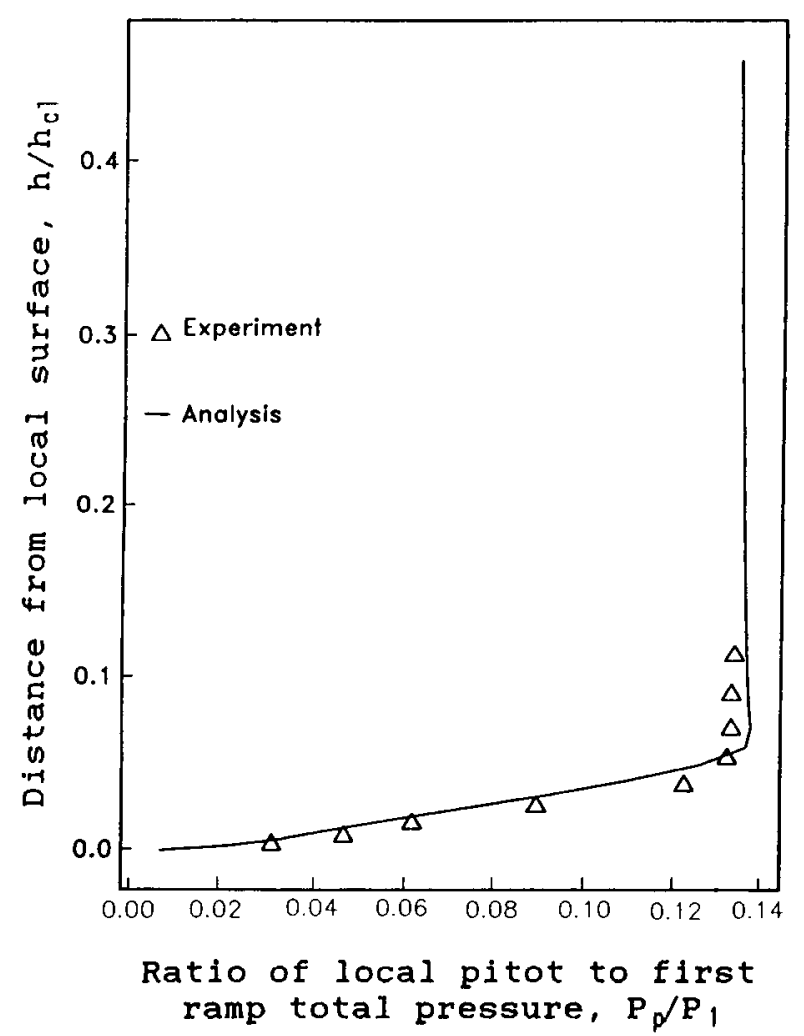

F1gure 41: PARC3D analysis / data comparison: ramp centerline boundary layer profile, station -3.0

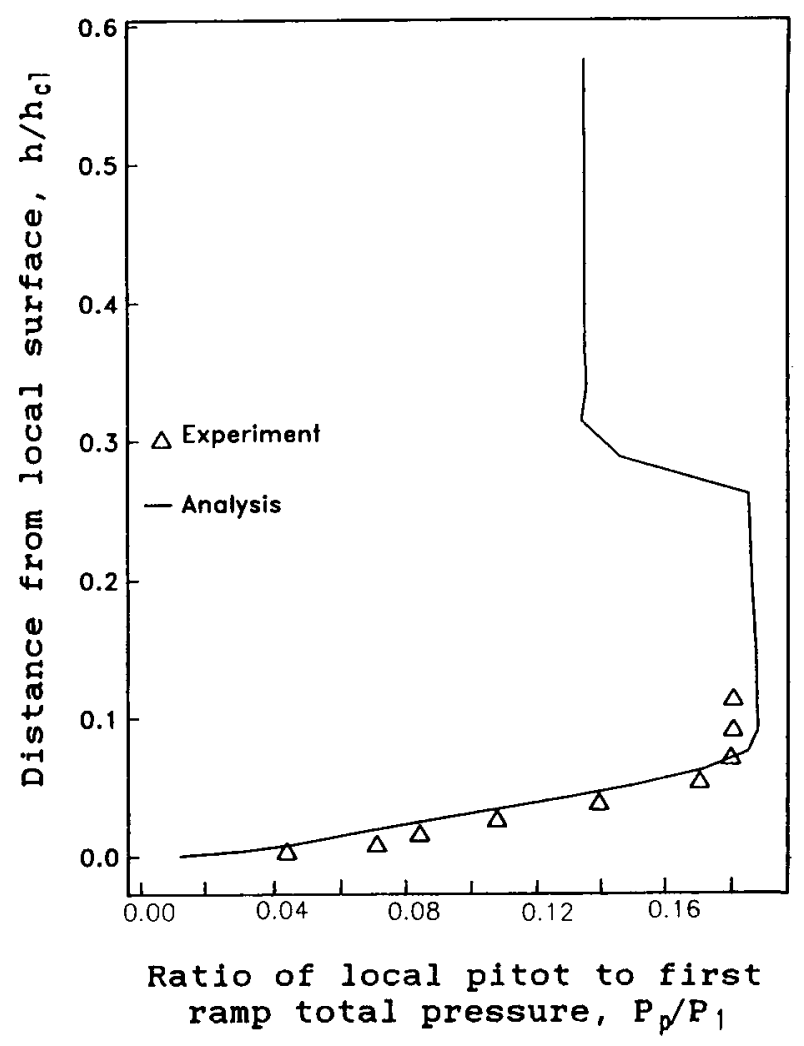

F1gure 42: PARC3D analysis / data comparison: ramp centerline boundary layer profile. station 17.2

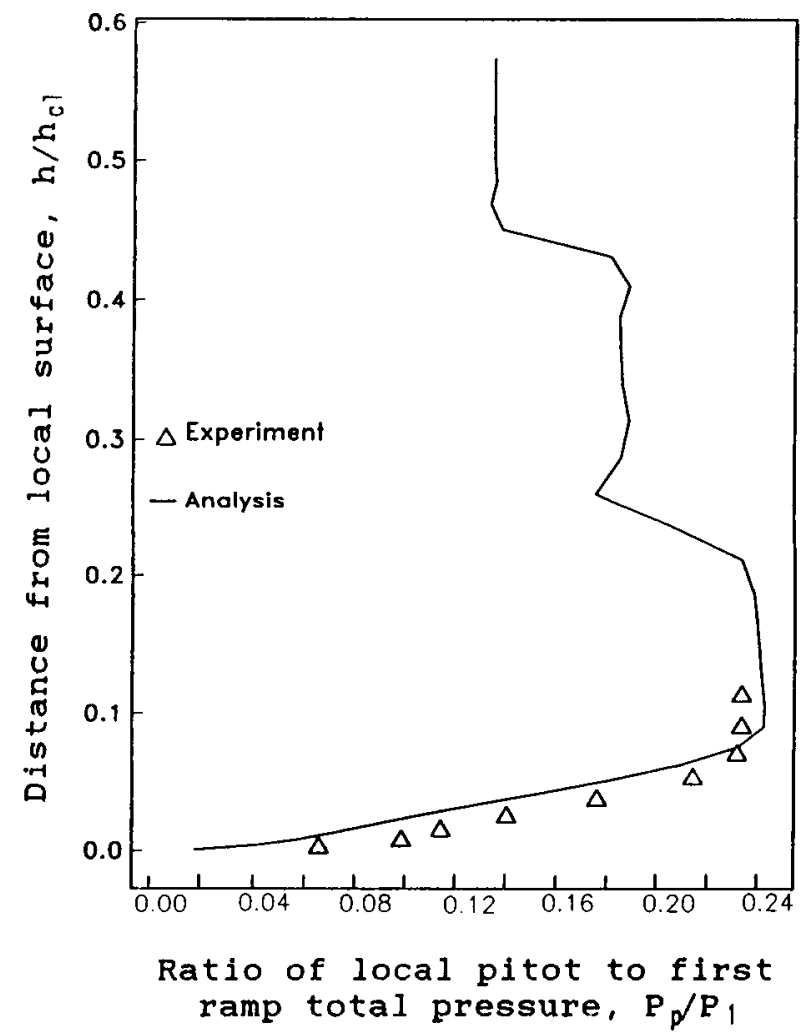

Pigure 43: PARC3D analysis / data comparison: ramp centerline boundary layer profile, station 30.5 


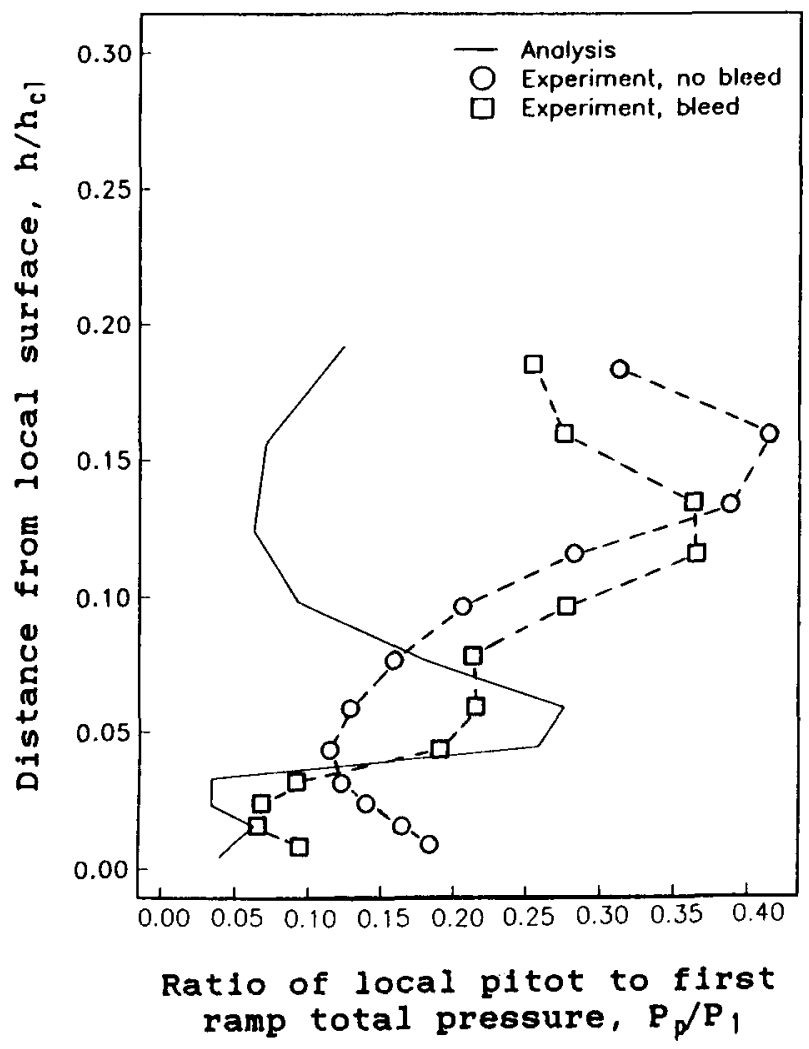

Pigure 44: PARC3D analysis / data comparison: cowl corner rake proflle, station 59.6

bleed experimental data. The code predicts "bumps" In the profile similar to the data, but on a much different vertical scale. Discrepancles between the analys $1 \mathrm{~s}$ and the experimental are currently being studied. An analysis which includes bleed representative of a configuration tested will be completed soon, and may provide closer comparisons to the data.

\section{CONCLUDING REMARKS}

The previous analyses would seem to indicate that the state of CFD has arrived to the point that, at least on a two-dimensional basis, it is doing a good job of predicting high speed flow fields. In areas of highly complex, three-dimensional flow, it is calculating flow flelds which are somewhat similar to reality, since unusual trends ("bumps" in pressure profiles on corner rakes) are being predicted which reseable the data in general shape, If not magnitude. Comparisons are, however, Just getting underway, and the analyses presented here represent the current status of ongoing efforts to calibrate and refine the CFD codes.

The Mach 5 inlet test has provided a set of data which is currently being employed by various organizations to calibrate high speed inlet analysis codes. The data is available to interested individuals, and may be obtained by contacting the author.

\section{REPERENCES}

1. Watts, J.D., et. al.: Mach 5 Cruise Aircraft Research. NASA CP-2398, Volume II, 1985.
2. Coltrin. R.E: High-Speed Inlet Research Progran and Supporting Analyses. Presented at Aeropropulsion ' 87 Conference, NASA Lewis Research Center, Cleveland, Ohio, November 1719, 1987. NASA $\mathrm{CP}-10003$

3. Perkins, E.W.; Rose, W.C.; and Horie, G.: Design of a Mach 5 Inlet System Model, NASA CR-3830, August, 1984 .

4. Benson, T.J.: Three-dimensional Viscous Calculation of Flow in Mach 5.0 Hypersonic Inlet, AIAA 86-1461, June, 1986

5. Anderson, B.H.: Three-dimensional Viscous Design Methodology for Advanced Technology Aircraft Supersonic Inlet Systens. NASA TM-83558, 1984.

6. Rose, W.C., and Perkins, E.W.: Innovative Boundary Layer Control Methods in High Speed Inlet System. Final Report, Phase I SBIR Contract No. NAS3-25408, NASA Lewis Research Center, September, 1988.

7. Cooper, G.K., Jordan, J.L., and Phares, W.J.: Analysis Tool for Application to Ground Testing of Highly Underexpanded Nozzles. AIAA 87-2015, 1987. 


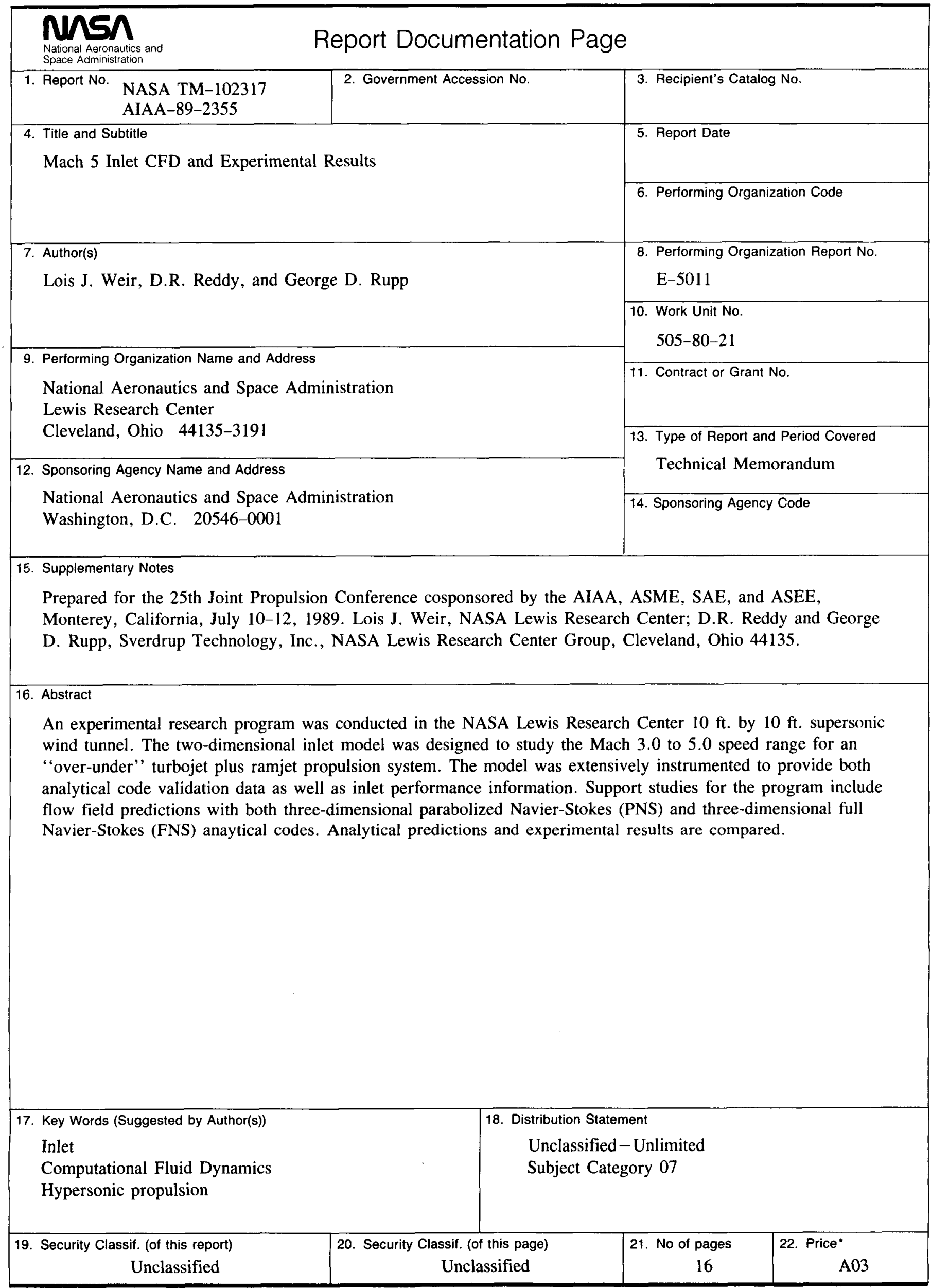

